OPEN ACCESS

Edited by:

Greta Gölz,

Freie Universität Berlin, Germany

Reviewed by:

Shilpi Agrawal,

University of Arkansas, United States

Melinda J. Mayer,

Quadram Institute, United Kingdom

${ }^{*}$ Correspondence:

Agnieszka Krystyna Wyszyńska

ak.wyszynska@uw.edu.pl

tThese authors have contributed equally to this work and share first authorship

Specialty section:

This article was submitted to

Food Microbiology,

a section of the journal

Frontiers in Microbiology

Received: 30 April 2021

Accepted: 23 August 2021

Published: 28 September 2021

Citation:

Wyszyńska AK and

Godlewska R (2021) Lactic Acid

Bacteria - A Promising Tool for

Controlling Chicken Campylobacter

Infection.

Front. Microbiol. 12:703441. doi: 10.3389/fmicb.2021.703441

\section{Lactic Acid Bacteria - A Promising Tool for Controlling Chicken Campylobacter Infection}

\author{
Agnieszka Krystyna Wyszyńska ${ }^{\star \dagger}$ and Renata Godlewska ${ }^{\dagger}$ \\ Department of Bacterial Genetics, Institute of Microbiology, Faculty of Biology, University of Warsaw, Warsaw, Poland
}

Since 2005, campylobacteriosis has been the most common zoonotic disease in Europe. The main reservoir of pathogenic Campylobacter strains is broilers, which makes raw and undercooked poultry meat two major sources of disease. Infection in chicken flocks is most often asymptomatic, despite a high level of colonization reaching $10^{6}-10^{9} \mathrm{cfu} / \mathrm{g}$ in animal ceca. It is widely believed that controlling the level of colonization of the birds' digestive tract by pathogenic strains is a good way to increase food safety. Many treatments have been proposed to combat or at least reduce the level of colonization in animals reservoirs: probiotics, bacteriophages, vaccines, and anti-Campylobacter bacteriocins. This review focuses on the effects of Campylobacter infection on the chicken microbiome and colonization control strategies using probiotics (mostly lactic acid bacteria, LAB), which are live microorganisms included in the diet of animals as feed additives or supplements. Probiotics are not only an alternative to antibiotics, which were used for years as animal growth promoters, but they also constitute an effective protective barrier against excessive colonization of the digestive system by pathogenic bacteria, including Campylobacter. Moreover, one of the many beneficial functions of probiotics is the ability to manipulate the host's microbiota. Recently, there have also been some promising attempts to use lactic acid bacteria as a delivery system of oral vaccine against Campylobacter. Recombinant LAB strains induce primarily a mucosal immune response against foreign antigens, accompanied by at most a low-level immune response against carrier strains. Since the main barrier against the invasion of pathogens in the gastrointestinal tract is the intestinal mucosal membrane, the development of effective oral vaccines to protect animals against enteric infection is very reasonable.

Keywords: microbiome, probiotic, poultry, lactic acid bacteria, Campylobacter

\section{INTRODUCTION}

Global population growth and the improvement of the economic situation around the world are causing an increased demand for meat. It is satisfied mostly by poultry and pork, whose consumption in 2017 exceeded 120 million tons (Scanes, 2007; Mordor and Intelligence, 2018). Attaining this scale was linked to significant changes in the livestock sector in recent decades. Traditional meat production methods were gradually replaced by industrial meat production, in which animals are kept indoors for most or all of the time. This negatively affects the 
intestinal microbiota of animals, resulting in a reduction of resistance to pathogens, impaired absorption of nutrients, increased mortality, and nutrition costs. In the past, a common solution to these problems was a regular administration of antibiotics (Dibner and Richards, 2005). Antimicrobials given to animals effectively reduced the development of pathogens, lowering the prevalence rate of gastrointestinal infections. Antimicrobial use has also led to an increase in the level of feed use by animals, increasing growth, and meat mass. On the other hand, the extended antibiotics dosing weaken a structure of the intestinal epithelium and function of the immune system, which can result in an increased incidence of diarrhea and mortality among animals (Morgun et al., 2015). Moreover, antibiotics at sub-therapeutic doses are known to induce the development of antibiotic resistance in both commensal and pathogenic bacteria. Commensals (e.g., E. coli) then serve as a long-lasting reservoir of antibiotic resistance genes that can be transferred to pathogens, including those dangerous to humans (Salyers et al., 2004; Andersson and Hughes, 2014; Ma et al., 2016). It has also been reported that antibiotic growth promoters administered to chickens (oxytetracycline, erythromycin, tylosin, bacitracin, and neomycin sulfate) increased the prevalence of Proteobacteria, which include a wide variety of human pathogens, such as Escherichia, Campylobacter, Salmonella, and Helicobacter (Looft et al., 2012; Salaheen et al., 2017).

Concerns over environmental and public health risks associated with the emergence of antibiotic resistance in zoonotic bacterial pathogens due to therapeutic and/or non-therapeutic use of antibiotics have led to a global interest in adopting more stringent use of antibiotics in food animal production. In the European Union (EU), the use of antibiotics as growth promoters (AGPs) in animal feeds has been banned since 2006 (Regulation (EC) No 1831/2003 of the European Parliament and of the Council of September 22, 2003 on additives for use in animal nutrition; Maron et al., 2013). At present, antibiotics may be given to animals only in justified cases upon recommendation and under control of a veterinarian. Despite these restrictions, overall sales of veterinary antimicrobial agents in 31 European countries in 2018 reached 6.5 thousand tons (EMA, 2020). For comparison, according to the FDA (Food and Drug Administration) by 2019, 11.46 thousand tons of antibiotics were sold in the United States for livestock (FDA, 2019). ESVAC (The European Surveillance of Veterinary Antimicrobial Consumption) and FDA reports show that 15 and $13.15 \%$ of these antibiotics were used in the European and US poultry industries, respectively. This was one of the reasons for an increasing pressure for stricter regulations in North America. The regulation issued by the US FDA that came into force on January 1, 2017 banned the use of antibiotics for enhancing growth in livestock (FDA, 2015). This rule prohibits the over-the-counter sale to farmers of antimicrobial drugs medically important for humans (EMA, 2017).

Reduced growth rates in animals that are observed in the absence of AGPs will impact the efficiency of production and perhaps jeopardize food security. It has also been reported that the ban on AGPs in poultry feed may lead to an increase in the therapeutic use of antibiotics, with enteric diseases and necrotic enteritis in particular as major indications (Hughes et al., 2008). Therefore, it became necessary to develop novel alternatives to growth stimulants that could strengthen the natural defenses of animals and thus prevent the expansion of pathogenic microflora in the gastrointestinal tract and at the same time exert a positive effect on animal breeding traits. That is the reason why the interest in probiotics and their possible use as food additives for animals has increased significantly in recent years.

\section{CAMPYLOBACTERIOSIS}

Among the foodborne diseases, zoonoses, which are infections transmitted from animals to humans (either directly or via the food chain), are of great importance. Studies indicate that between a third and up to a half of all human infectious diseases have a zoonotic origin (EFSA, 2016). Since 2005, campylobacteriosis has been the most commonly diagnosed zoonosis in the residents of the EU Member States. According to data from the European Food Safety Authority in EFSA (2016), 220,682 cases of Campylobacter infections were confirmed, with an incidence rate 59.7 per 100,000 (EFSA and ECDC, 2021). However, since most infections are mild, only one in 47 cases of campylobacteriosis is reported; thus, the number of Campylobacter infections is grossly underestimated (Havelaar et al., 2013).

Campylobacteriosis is a result of infection with thermotolerant Campylobacter bacterial strains. Although new species of Campylobacter have been recently discovered, human cases of campylobacteriosis are dominated by two main species, Campylobacter jejuni and, to a lesser extent, Campylobacter coli. Limited data are available on infections caused by other species, i.e., Campylobacter lari or Campylobacter fetus (Kaakoush et al., 2015). The course of Campylobacter infection depends on the pathogenicity of the strain and on the responsivity of the host's immune system. The clinical manifestation is variable and ranges from asymptomatic to acute intestinal inflammation accompanied by a long-lasting, mucoid diarrhea. Symptoms usually resolve spontaneously after about 7 days; however, Campylobacter infections sometimes lead to the development of autoimmune and neurological diseases, examples of which are reactive arthritis and neuropathy of the peripheral nervous system, i.e., Guillain-Barré syndrome (Dasti et al., 2010; Goodfellow and Willison, 2016). Current studies indicate that Campylobacter infections may also be associated with irritable bowel syndrome (IBS) and colorectal cancer (Kaakoush et al., 2015). A small percentage of patients with Campylobacterinduced enterocolitis develop bacteremia (Robyn et al., 2015).

Although the infection may be also caused by the consumption of water, unpasteurized milk or beef contaminated by pathogens, epidemiological studies show that the majority of cases of campylobacteriosis is caused by the consumption of infected, inadequately prepared poultry, consistent with the observation that the main reservoir of Campylobacter is farm poultry and wild birds (Dasti et al., 2010; Silva et al., 2011). According 
TABLE 1 | Proposed strategies to control the Campylobacter infection for use on farms.

\begin{tabular}{|c|c|c|}
\hline Strategy & $\begin{array}{l}\text { Preventive measures } \\
\text { against Campylobacter } \\
\text { infection }\end{array}$ & $\begin{array}{l}\text { Measures to reduce } \\
\text { Campylobacter } \\
\text { infection }\end{array}$ \\
\hline $\begin{array}{l}\text { Good hygienic practices } \\
\text { and biosecurity }\end{array}$ & Hald et al., 2007 & Lin, 2009 \\
\hline $\begin{array}{l}\text { Treatment of drinking } \\
\text { water }\end{array}$ & Chaveerach et al., 2002 & Byrd et al., 2001 \\
\hline $\begin{array}{l}\text { Diet modification } \\
\text { (antimicrobial additives } \\
\text { in water and food) }\end{array}$ & $\begin{array}{l}\text { Guyard-Nicodeme et al., } \\
2016\end{array}$ & $\begin{array}{l}\text { Hilmarsson et al., 2006; } \\
\text { De Los Santos et al., } \\
2009\end{array}$ \\
\hline Vaccination & $\begin{array}{l}\text { Buckley et al., 2010; } \\
\text { Layton et al., 2011; } \\
\text { Kobierecka et al., 2016b; } \\
\text { Nothaft et al., } 2016\end{array}$ & - \\
\hline Passive immunization & $\begin{array}{l}\text { Sahin et al., 2003; } \\
\text { Vandeputte et al., } 2019\end{array}$ & $\begin{array}{l}\text { Tsubokura et al., 1997; } \\
\text { Hermans et al., } 2014\end{array}$ \\
\hline Bacteriophage therapy & - & $\begin{array}{l}\text { Loc Carrillo et al., 2005; } \\
\text { Wagenaar et al., 2005; } \\
\text { Kittler et al., } 2013\end{array}$ \\
\hline Bacteriocin & - & $\begin{array}{l}\text { Stern et al., 2005, 2006; } \\
\text { Zommiti et al., } 2016\end{array}$ \\
\hline Probiotic & $\begin{array}{l}\text { Arsi et al., 2015; Manes- } \\
\text { Lazaro et al., } 2017\end{array}$ & $\begin{array}{l}\text { Morishita et al., 1997; } \\
\text { Neal-McKinney et al., } \\
2012\end{array}$ \\
\hline Prebiotic & $\begin{array}{l}\text { Baurhoo et al., 2009; Kim } \\
\text { et al., } 2019\end{array}$ & - \\
\hline $\begin{array}{l}\text { Genetic selection of } \\
\text { chicken (breeding of } \\
\text { chickens lines resistant } \\
\text { to Campylobacter } \\
\text { colonization) }\end{array}$ & $\begin{array}{l}\text { Boyd et al., 2005; Kaiser } \\
\text { et al., 2009; Swaggerty } \\
\text { et al., } 2017\end{array}$ & - \\
\hline
\end{tabular}

to the report in EFSA (2016), as many as $29.6 \%$ of the tested fresh broiler carcasses in Europe were contaminated with Campylobacter (EFSA and ECDC, 2021). This figure is lower than in previous years, when on average $38 \%$ of the meat samples contained Campylobacter. Notably, the rate of Campylobacter-positive samples of broiler meat varied greatly between individual members of the European Union (EFSA and ECDC, 2017, 2021). It is important to note that the data from various investigations often are not directly comparable because of differences in sampling strategies and testing methods, including sampling season (in most countries, Campylobacter infections are known to be more prevalent in poultry during the summer than during the winter).

A large number of cases, the occurrence of post-infectious complications (mainly neurological ones), as well as the growing prevalence of Campylobacter strains resistant to antibiotics make campylobacteriosis a serious problem for medical services. Campylobacter, mainly due to its antibiotic resistance, forced its way to the list of bacterial species constituting the greatest threat to human health, published 2017 by the World Health Organization (WHO). ${ }^{1}$ Therefore, in recent years, researchers

${ }^{1}$ https://www.who.int focused on developing a strategy to prevent Campylobacter infections. It seems that controlling the level of colonization of the digestive tract of animals should improve food safety. For example, it has been determined that a reduction in the C. jejuni chicken carcass contamination by 2 log would reduce the risk of campylobacteriosis in humans 30-fold (Rosenquist et al., 2003; EFSA Panel on Biological Hazards (BIOHAZ), 2011). Table 1 provides various approaches that are being developed to control the Campylobacter infection on farms. Some of them are promising and results of using others are modest and variable.

\section{MICROBIOME OF CHICKENS}

Studies of various animal species, including humans, have shown that the intestinal microbiota has a huge impact on the health of the host, and the disturbance of its balance (dysbiosis) is associated with the occurrence of various diseases, such as inflammatory bowel disease, IBS, obesity, and diabetes (Turnbaugh et al., 2006). Since the ban on AGP in animal feed, these dysbiosis-related problems have become a major issue, especially in intensive animal farming.

The gut microbiome of a healthy animal is quite stable, although its composition and activity depend on many factors. It may change as a result of viral or bacterial infections or of treatment with antimicrobials (Ley et al., 2008; Yegani and Korver, 2008; Costa et al., 2015; Kumar et al., 2018). It is also determined by zoohygienic conditions, age (Mueller et al., 2006; Williams et al., 2013), health status (Abt and Artis, 2009), mental stress, and genetic factors (Meng et al., 2014; Mandal et al., 2020).

The digestive tract of poultry hosts at least 900 species of microorganisms (Apajalahti et al., 2004). The majority of them belong to a commensal microflora, which stimulates the production of cytokines (i.e., tumor necrosis factor) and through them, impacts on the activity of lymphocytes and other mucosal subpopulations of host immune cells (Atarashi and Honda, 2011; Meijerink et al., 2020). The intestinal bacteria are also of high importance for the gut barrier function as they regulate the proliferation and differentiation of intestinal epithelial cells (Pan and Yu, 2014). The metabolic abilities of bacteria forming the intestinal microbiome enable the degradation of complex food substrates (e.g., plant cell wall components). The final products of the fermentation of the resulting simple sugars are short-chain fatty acids (SCFA), which become an important source of energy and carbon for the host (Sergeant et al., 2014).

The number of pathogenic microorganisms in the digestive tract of a healthy farm animal is usually low, constantly controlled by other microorganisms in the intestinal ecosystem and does not pose a serious threat to the host health. Intestinal microbiota contributes to the host defense in multiple ways, but one of the most important ones is called a "competitive exclusion." In healthy animals, commensal bacterial communities in the GI tract colonize intestinal mucosa and form a layer covering the mucosal surface. This layer of microbial communities can effectively block the attachment and subsequent colonization 
by most invading enteric pathogens (Lan et al., 2005). Moreover, changes of the intestinal $\mathrm{pH}$, modulation of the oxygen level, and the utilization of nutrients carried out by intestinal microbiota help to generate an unfavorable environment to pathogens (Sekirov et al., 2010). Thus, a stable healthy gut microbiota is an effective barrier against the colonization of pathogens. The microbial community has also an important role in modulating the host immune system, maintaining normal physiological homeostasis, and influencing host metabolism (Sommer and Backhed, 2013). Thus, all alterations in its composition may have adverse effects on birds' health and on an efficiency of energy extraction from feed.

The development of high-throughput sequencing approaches provided an opportunity for an in-depth investigation on the taxonomic composition of the poultry intestinal microbiome. It seems that understanding how the gut microbiota of chickens is shaped will help in the development of effective probiotics or other successful interventions aimed at chicken's health.

In the majority of poultry farms, microorganisms that form the microbiome of the chicks' digestive system come from the breeding environment. That is, why large differences in microbiota composition are observed immediately after hatching (Pedroso et al., 2005). Since farm chickens do not have contact with adult birds, re-use of litter is a common practice in the production of broilers. Cressman et al. demonstrated that the ileal mucosal microbiome of chickens reared on fresh litter was dominated by Lactobacillus spp., whereas a group of unclassified Clostridiales was the dominating bacteria in chickens reared on reused litter (Cressman et al., 2010).

The "natural" core microbiome of broiler chickens is difficult to define, and this is the consequence of a high variability not only between birds, but also between whole flocks or even breeds (Pandit et al., 2018; Richards et al., 2019). Nevertheless, the short transit time of food, a consequence of the shortness of the gastrointestinal system of birds, promotes bacteria that adhere to the mucosal layer and/or grow fast (Pan and Yu, 2014). The most diverse microbiome is the cecal one. This is favored by the longest feed retention time (12-20 h; Singh et al., 2012). The cecum is dominated by representatives of the Clostridiaceae, Bacteroidaceae, Lactobacillaceae, and Lachnospiraceae families (Witzig et al., 2015; Richards et al., 2019). The diversity and distribution of bacterial species that make up the GIT microbiota initially fluctuate but become well established as soon as by day 3 post-hatch (Apajalahti et al., 2004) or, in another study, by day 11 (van der Wielen et al., 2002). In turn, a rapid increase in diversity up to day 12 with variation observed both in terms of genera and abundance, before the stabilization of the microbial diversity after day 20 was observed by Ijaz et al. (2018). On the 42nd day of life of chickens over 200 species were identified in their intestines, while after hatching, only 50 were found (Oakley et al., 2014a). Initially, the intestinal microbiome is dominated by Gram-negative bacteria, in particular Enterobacteriaceae (Salmonella, Klebsiella, Proteus, and E. coli). In week-old chicks, representatives of Firmicutes (Lachnospiraceae, Ruminococcaceae, Clostridiales, Christensenellaceae, and Bacillaceae) and Bacteroidetes (Bacteroidaceae) emerge (Ballou et al., 2016; Kumar et al., 2018;
Richards et al., 2019) and gradually begin to prevail. On the 28th day of birds' life according to the Ballou et al. study, Gram-negative bacteria account for less than $6 \%$ of the microbiome. The arrival of the SCFAs producers, i.e., Lachnospiraceae, Ruminococcaceae, and Bacteroidaceae, may explain the gradual decrease in the presence of Enterobacteriaceae in young birds' intestines (Figure 1); thus, early interventions promoting this effect might be highly desirable.

A comparison of the microorganisms presents in the lumen of the intestine with those associated with the mucous membrane showed a much greater diversity of the latter, especially in the ileum and the cecum (Borda-Molina et al., 2016). Pseudomonas spp. - species that have the ability to hydrolyze phytate or to degrade starch and improve the availability of plant phosphorus - have been identified only in the mucosa of the ileum (Maougal et al., 2014). In the mucous membrane, species belonging to the genera Clostridium XI and Ralstonia were also present in large numbers, whereas Lactobacillus sp. strains were three times more abundant in the lumen of the ileum (Borda-Molina et al., 2018). The difference in lumen and mucous microbiota composition was also observed by Richards et al. (2019).

A close relationship between the composition of the microflora and the productivity of the poultry has been identified (Stanley et al., 2013, 2016; Clavijo and Florez, 2018; Johnson et al., 2018). Animals with a high feed conversion ratio (FCR) exhibited a higher abundance of the genera of Acinetobacter, Bacteroides, Streptococcus, Faecalibacterium prausnitzii, Clostridium (from families Lachnospiraceae, Ruminococcaceae, and Erysipelotrichaceae), and Lactobacillus. Simultaneously, a negative correlation between performance parameters and Enterobacteriaceae expansion has been reported (Singh et al., 2014; Stanley et al., 2016). Other bacterial taxa, strongly correlated with broiler chicken performance, were identified by Johnson et al. and included as: Butyricimonas, Candidatus division Arthromitus, Faecalibacterium, Parabacteroides, and Sutterella (Johnson et al., 2018).

Consequently, in the gut of normal, healthy, and non-stressed animals, there is a dynamic balance between beneficial and non-beneficial bacteria. On farms, this balance can be disturbed, for example, by various stress conditions which animals may be exposed to. In the poultry production systems, these include transportation, change or withdrawal of food and water, and a high density of individuals in a relatively small space. All kinds of stress, both physiological and psychological, weaken the immune system, which leads to intestinal dysfunction, increases the permeability of the intestinal barrier, and predisposes to the colonization of the digestive tract by pathogenic microorganisms (Mandal et al., 2020).

\section{THE EFFECT OF CAMPYLOBACTER INFECTION ON CHICKEN MICROBIOME}

In industrialized countries, Campylobacter is the most common cause of bacterial foodborne infections (Hermans et al., 2012b). Two species responsible for the majority of human 


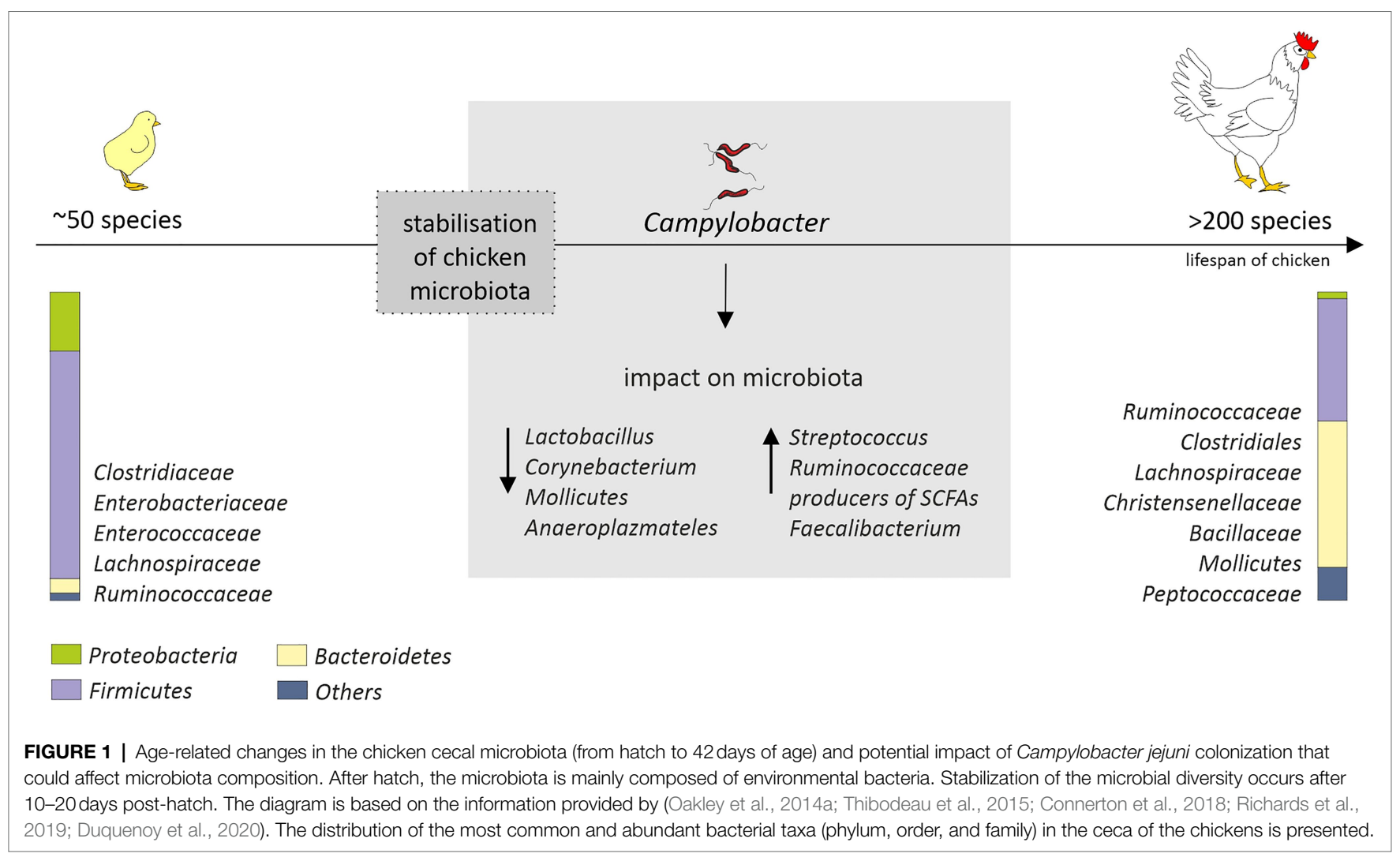

diseases, C. jejuni and coli, are extremely widespread in the production of poultry. Campylobacter mainly colonizes lower parts of the digestive tract of birds, and the level of colonization is very high, up to $10^{9} \mathrm{cfu} /$ gram of cecal contents (Sahin et al., 2015). Even such a high level of colonization does not cause disease symptoms in birds, which prevents the elimination of infected individuals from the flock. It has been suggested that persistent, high-level cecal colonization of C. jejuni in its avian host stems from an inefficiency of the chicken immune system combined with mechanisms redirecting the response toward tolerance (Hermans et al., 2012a). Most previous studies indicate that Campylobacter is a poultry commensal (Lee and Newell, 2006), but there are also results which report detrimental health effects associated with the colonization of chicken gastrointestinal tract by C. jejuni (Williams et al., 2013; Humphrey et al., 2014; Awad et al., 2015). Noticed in Humphrey et al. (2014) that broiler gut mucosa was damaged by C. jejuni M1 strain: high level of inflammation occurred, leading to a diarrhea and consequent poor bird welfare (Humphrey et al., 2014). The ability to induce intestinal damage and to modulate the barrier function of the intestinal epithelia facilitates the paracellular passage of $C$. jejuni into the underlying tissues and supports the translocation of luminal bacteria, such as E. coli to internal organs (Lamb-Rosteski et al., 2008; Kalischuk et al., 2010; Awad et al., 2015, 2016). Similar clinical symptoms have been seen by other research groups (Ghareeb et al., 2012; Awad et al., 2015, 2018). It appears that the outcome of infection depends on the genetic interplay between the host and Campylobacter strain.

C. jejuni is rarely detected in gastrointestinal tract of commercial flocks under 2 weeks of age, regardless of the production system (Conlan et al., 2007; Newell et al., 2011). This suggests that a mechanism counteracting colonization of young birds by Campylobacter exists. It has been speculated that a high level of specific maternal antibodies provides protection from Campylobacter colonization (Cawthraw and Newell, 2010). Observations that chickens residing in flocks together with adults are free of Campylobacter for the first few weeks after hatching seem to confirm this notion (Sahin et al., 2003).

There are also reports suggesting that a strong shift in the bacterial microbiome is a leading cause for an age-dependent infection of chickens with Campylobacter (Han et al., 2016). But at the same time, it has been shown that chickens between 0 and 3 days of age, whose microbiome is composed of species very different from those found in $2-3$ week old chickens, can become infected with Campylobacter and shed the bacterium. These observations are purely experimental and differ from those obtained in the field (Conlan et al., 2007). In turn, Conlan et al. suggest that the mechanism behind the "lag-phase" reported in commercial flocks results from the age-dependent transmission between hosts rather than from their susceptibility to colonization (Conlan et al., 2011). This is supported by studies conducted by Connerton et al., which indicate that chickens can become infected at any time during the rearing 
period, but the colonizing Campylobacter only multiplies to the extent of being detectable and efficiently transmittable when birds are over 2 weeks old (Connerton et al., 2018). Recently Ijaz et al. have performed comprehensive day-to-day investigation of the chicken cecal microbiome from day 3 to 35 . They identified Campylobacter at day 16, just after the most substantial changes in metabolic profiles observed, and hypothesized that a shift from competitive to environmental drivers of microbial community from days 12 to 20 creates a window of opportunity whereby Campylobacter appears (Ijaz et al., 2018).

Although the chicken microbiome is being increasingly characterized, information on the effect of foodborne pathogens on its modulation/composition is still lacking. Only a few studies have reported changes in the chicken microbiota in response to Campylobacter colonization.

In studies conducted by Kaakoush et al., a presence of $C$. jejuni in the chicken gastrointestinal tract was associated with a lower abundance of Lactobacillus and Corynebacterium and a higher abundance of both Streptococcus and Ruminococcaceae in fecal samples (Kaakoush et al., 2014; Figure 1). Also a presence of major producers of SCFA (Bacteroides, Alistipes and Blautia) was noted. Since C. jejuni can use organic acids produced by these genera as an energy and carbon sources, this could, at least partially, explain their co-occurrence in infected birds. In this experiment, a modulation of the microbiome was assessed in birds originating from different farms and production types. Chicken microbiome modifications induced solely by $C$. jejuni during a controlled experimental challenge was measured in the studies carried out by Thibodeau et al. (2015). They noticed a link between C. jejuni and Clostridium, which is also a producer of SCFA. They hypothesized that $C$. jejuni could act as a hydrogen sink that would improve the growth of some Clostridium and their competitive standing through increased fermentation, leading in consequence to increased production of organic acid that can be used by the Campylobacter. Variable shifts in the abundance of members of the Clostridiales in response to Campylobacter colonization were observed also by Connerton et al. (2018). However, they noticed that several clostridial OTUs (most notably Clostridium $\mathrm{XIVa)} \mathrm{show} \mathrm{a} \mathrm{greater} \mathrm{an} \mathrm{abundance} \mathrm{in} \mathrm{the} \mathrm{absence} \mathrm{of} C$. jejuni. In the human gut, representatives of this group are major butyrate-producing bacteria and play a key role in maintaining metabolic and immune functions (Lopetuso et al., 2013). The presence of $C$. jejuni in the chicken gastrointestinal tract was also associated with a diminution of the relative abundance of Mollicutes and Anaeroplasmateles (Thibodeau et al., 2015). In recently conducted studies, a high level of Campylobacter has been also linked to a higher abundance of Faecalibacterium (Duquenoy et al., 2020). The positive interaction of these species has not yet been fully explained. Butyrate produced by Faecalibacterium is harmful to Campylobacter but may also trigger the expression of $C$. jejuni genes that are important for host colonization (Duncan et al., 2004; Van Deun et al., 2008). Faecalibacterium prausnitzii has also been found to be involved in the modulation of mucin production by goblet cells (Wrzosek et al., 2013). The production of mucus could have a beneficial effect for Campylobacter as the mucous layers provide a protective niche for them, allowing to resist intestinal peristalsis and the action of organic acids. The importance of Faecalibacterium has also been highlighted in a recent study conducted by Patuzzi et al. Their network analysis showed that Limnobacter, Parabacteroides, Pseudomonadaceae, Sutterella, Sphingobium, and Oxalobacteraceae were positively affected by Faecalibacterium and Lactobacillus, and at the same time, a negative interaction from Campylobacter was detected toward them. The author hypothesized that these six taxa might be involved in the maintenance of the resilience within the microbial community (Patuzzi et al., 2021). This is in line with the theory put forward by Duquenoy et al. Increased abundance of Faecalibacterium prausnitzii, which has a documented anti-inflammatory effect, would improve the ability of Campylobacter-colonized chickens to control inflammation caused by this microorganism (Duquenoy et al., 2020). Therefore, the importance of Faecalibacterium for chicken intestinal health remains to be determined.

It is conceivable that the chicken cecal microbiome is not extensively disturbed by colonization with $C$. jejuni. Elucidation of the role of gut microbiota in C. jejuni infection in chickens thus requires a more detailed understanding of their ecology. For the time being, the role of the chicken microbiota composition for the susceptibility to Campylobacter infection remains elusive.

In addition to microbiota, Connerton et al. have compared inflammatory responses, and zootechnical parameters of broiler chickens not exposed to Campylobacter with those exposed either at young age (6 days old) or at 20 days old, when commercial broiler chicken flocks usually become colonized. A transient growth rate reduction was observed only during early colonization. Both early and late colonization produce pro-inflammatory responses, but their kinetics are quite different. For birds infected on day 6 , first a relative increase in IFN- $\gamma$ and IL-4 was observed and then expression of IL-6, IL-17A, and IL-17F increased. These pro-inflammatory cytokines declined after upregulated expression of IL-10. Ultimately, cytokines in the early colonized birds returned to levels not distinguishable from age-matched noninfected birds (Connerton et al., 2018). Cytokine expression in response to Campylobacter infection in chickens challenged at day 20 demonstrated the upregulation of IL-6, IL-17A, and IL-17F; elevated IL-17A response was observed until the 35 day of life. These differences do not result in lower Campylobacter colonization levels at the end of the study but can lead to shifts in the resident microbial communities (Connerton et al., 2018).

Changes in the levels of pro-inflammatory, anti-inflammatory, and regulatory cytokines in Campylobacter-infected chickens were also observed by Mortada et al. A study of the effects of this pathogen on $\mathrm{CD} 4+$ and $\mathrm{CD} 8+$ cells throughout the life of chickens showed that Campylobacter is capable of inducing both Th1 and Th2 immune responses. The ability to maintain the balance between them might explain a high level of cecum colonization in Campylobacter-infected birds with no pathological changes (Mortada et al., 2021).

Developing effective probiotic-based strategies for controlling Campylobacter infection in chickens certainly require understanding of the interaction of this pathogen with the 
chicken microbiota as well as its influence on the functioning of birds' immune system.

\section{LACTIC ACID BACTERIA AS PROBIOTICS}

Probiotics are currently defined as mono or mixed cultures of live microorganisms, which - when administered in adequate amounts - confer a health benefit to the host (FAO-WHO, 2006). Their action, consisting mainly of antagonistic activity against pathogens and modulation of the immune system, is important in maintaining the balance of intestinal microflora. Most commonly used probiotic preparations contain lactic acid bacteria (LAB), although they can also be formulated using bacteria from outside of this group, as well as fungi showing beneficial effects on health (Sarao and Arora, 2017). LAB is an artificially extracted group with a huge genetic and phylogenetic diversity. These are Gram-positive, nonsporulating, catalase-negative, acid-tolerant, anaerobic or aerotolerant, and auxotrophic bacteria characterized by the ability to convert carbohydrates into lactic acid via fermentation. Its most numerous representatives are bacteria of the genera Lactobacillus and Bifidobacterium. This group also includes microorganisms belonging to such genera as: Enterococcus, Lactococcus, Leuconostoc, Pediococcus, and Streptococcus.

The LAB has been used for millennia in the production of fermented foods. They are "generally regarded as safe" (GRAS status) according to The American Food and Drug Administration. Several species, including Lactobacillus plantarum and Lactobacillus fermentum, have received a qualified presumption of safety status given by European Food Safety Authority (EFSA).

The mechanism of the beneficial effect of probiotics is not fully understood. It is primarily based on interaction with a complex microbiome on the surface of the intestinal epithelium. Probiotics compete with pathogenic microorganisms for sites of adhesion to intestinal epithelial cells. They can also produce various compounds that inhibit the growth of pathogens, such as organic acids, hydrogen peroxide and bacteriocins (small proteins with specific bactericidal activity), and compete for available nutrients, which makes the environment less permissive for the growth of pathogens ( $\mathrm{Ng}$ et al., 2009; Bermudez-Brito et al., 2012; Peng et al., 2016; Oh et al., 2017). Probiotic bacteria also play a role in improving barrier function by enhancing the expression of genes involved in epithelial tight junction formation and by increasing synthesis of mucin that forms mucus, a layer protecting from pathogens, enzymes, toxins, dehydration, and abrasion. The positive effects of probiotics manifest themselves also through increased activity of digestive enzymes and improved breakdown of indigestible nutrients. Studies conducted so far indicate that probiotics can modulate and regulate intestinal immune responses by reducing pro-inflammatory cytokines, increasing secretory IgA production, and promoting specific and non-specific immune responses against pathogens (activation of macrophages; Haghighi et al., 2008; Ng et al., 2009; BermudezBrito et al., 2012; Martinez et al., 2016).
Several interesting reviews were published recently that describe mechanisms of probiotics action in details (Khan et al., 2020; Tarradas et al., 2020). We summarize these findings in Figure 2.

\section{The Impact of Probiotics on Chickens' Microbiota}

For decades, various approaches have been used in animal husbandry with aim to influence the composition of animal gut microbiome. However, due to dramatic deficiencies in former research methods, there was little understanding of the complexity of the intestinal microbial population and its relationship to animal health. The introduction of highthroughput DNA-based molecular biology techniques, such as metagenomics and new generation DNA sequencing, completely changed this picture. These methods allow for characterization of uncultivable members of intestinal microbiota, thus shedding light on the composition and temporal spatial location of the microbial population in animal intestine. One of the effects that is attributed to probiotics is to improve the health and performance of farm animals by manipulating the host microflora. In the case of broilers, it was shown that supplementation of food with probiotics is capable to accelerate the growth rate, which may be associated with increased food absorption. Another reason for a more efficient use of feed may be the production of numerous carbohydrate-degrading enzymes, such as $\beta$-glucans (He et al., 2019; Sureshkumar et al., 2021).

Manipulation of the microbiome through probiotics has long been used by the poultry industry to increase growth rates and feed conversion and to improve gut health of chickens. However, there are quite conflicting data on the actual ability of probiotics to stimulate the growth of chickens. Some studies demonstrated that supplementing feed with probiotics cultures can enhance body weight gain and feed efficiency and reduce mortality rate in broilers (Timmerman et al., 2006; Salim et al., 2013; De Cesare et al., 2017). Others observed that colonization of the lower portion of the small intestine by Lactobacillus strains may negatively affect the performance of chickens (Oakley et al., 2014b). And some indicate no significant effects on host feed consumption and the feed-to-growth conversion ratio (Nakphaichit et al., 2011). The positive health effect is also brought by the administration of probiotics to alleviate the side effects of antibiotic treatment. But one should keep in mind that interactions between host and microbiota are complex and may also have negative effects (Rinttila and Apajalahti, 2013).

Unfortunately, for a long time, technical limitations have made it difficult to check whether the use of live bacterial preparations affects the composition and diversity/development of the microbiome. We can now determine how these treatments affect the microbiota and the host, and this understanding will allow us to use more targeted approaches in the future. Ballou et al. (2016) characterized the microbiome of chickens that were administered live bacterial preparations commonly used in the production of poultry: live attenuated S. enterica, sv. Typhimurium (Salmune ${ }^{\circledR}$, CEVA Biomune) and a probiotic feed supplement composed of representatives of the LAB group: 


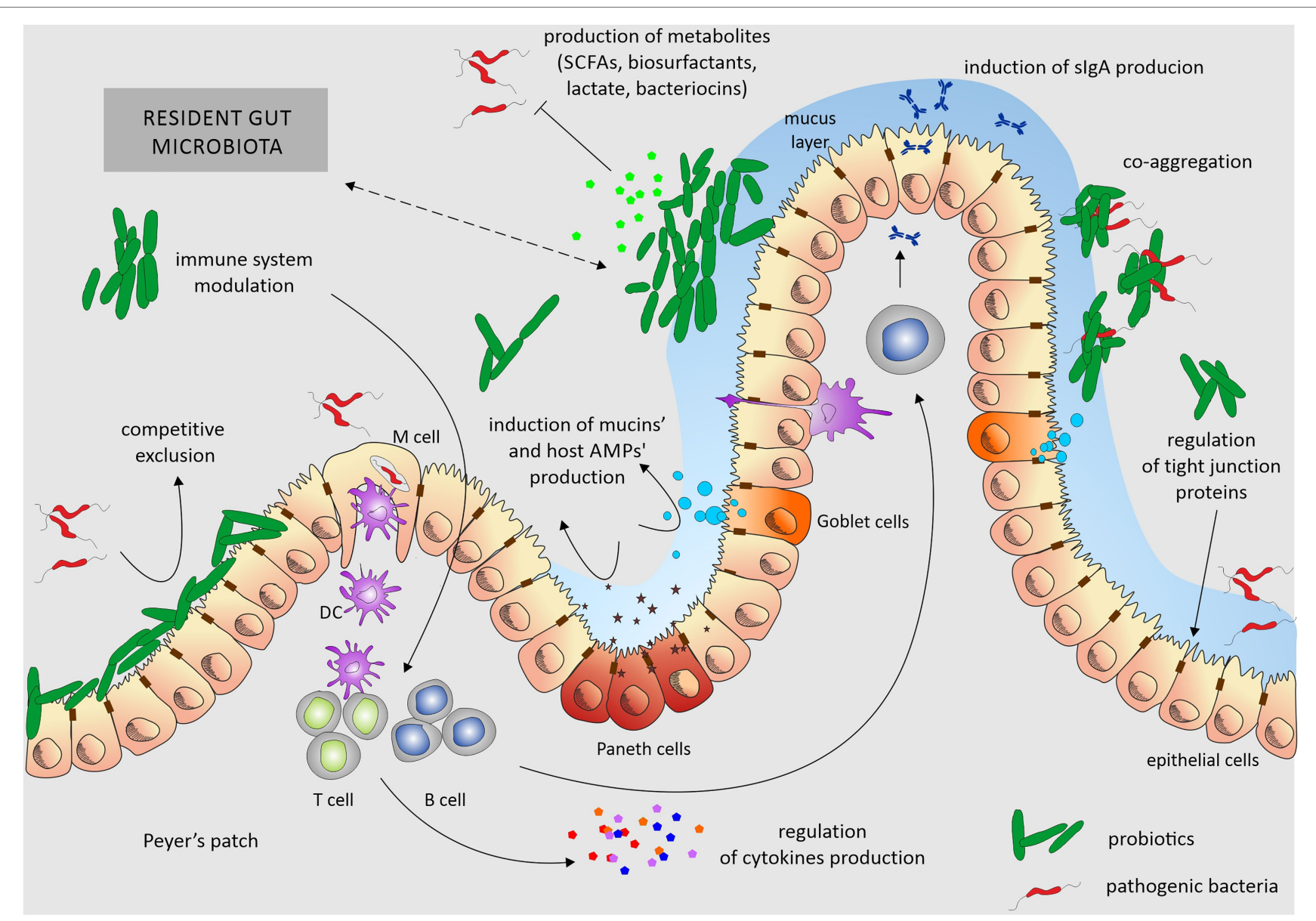

FIGURE 2 | Overview of mechanisms of probiotics' action. Probiotics exert their beneficial effects mainly by ensuring the proper balance of the microbiota colonizing the gut. Probiotic activity depends on stabilization of the epithelial barrier, induction of mucin secretion, and aggregation skills. By adhering to enterocytes, they reduce the opportunity for the colonization of this ecological niche by pathogenic bacteria. They also produce various, not always fully characterized, metabolites that inhibit the growth of pathogens. Additionally, they modulate the host immune system. Probiotics influence the gut through one or a combination of these mechanisms. Dotted arrow underlines the interplay between the host microbiota and probiotic strains and nature of these interactions can be both - positive, negative, depending on the composition of resident gut microbiota and used probiotic. DC, dendritic cells.

Lactobacillus acidophilus, Lactobacillus casei, Enterococcus faecium, and Bifidobacterium bifidum (PrimaLac ${ }^{\circledR}$, Star Labs). Studies have shown that a single administration of the Salmonella strain and a daily intake of a probiotic dietary supplement change the microbiota of growing chickens. These differences, mainly related to changes in the amount of microorganisms forming microbiome, were sustained throughout the study. However, although the use of probiotics and bacterial vaccines affects the taxonomic composition of the microbiome, it has only a temporary or minor effect on the function and activity of the microbiome in non-stress growth conditions (Ballou et al., 2016). It cannot be ruled out that the main advantage of using probiotic strains in animal production is to enable a quick restoration of a disturbed or stunted microbiome to the normal functional state. Another advantage is that probiotics do not have a deleterious impact on microbial diversity. This is in stark contrast with antibiotics: it was found that the exposure of mice to antibiotics at an early age of life can induce deleterious changes in the microbiome that can persist even for several months after treatment (Nobel et al., 2015; Grazul et al., 2016).

Baldwin et al. also have checked how the administration of probiotics affects the composition of the microbiome. They assumed that the best opportunity to achieve a permanent colonization in birds and influence the development of microbiota is the early period of life, before the microbiome has established itself - in other words, that early inoculum may shape the gut microbiota of chickens for life. Therefore, they administered an inoculum of selected beneficial strains (Lactobacillus ingluviei, Lactobacillus agilis, and Lactobacillus reuteri), capable of persistently colonizing poultry, to one-day hatch chicks (single dose). The resulting changes in the probiotic group consisted of reduction in Alistipes- and Ruminococcus-related species (Baldwin et al., 2018). Probiotic treatment also increased Bacteroides uniformis species, which is known to have the potential to degrade the isoflavones in the gut and significantly improve metabolic and immunological dysfunction in mice with diet-induced obesity (Renouf and Hendrich, 2011; 
Gauffin Cano et al., 2012). The presence of the best-colonizing inoculated strain was higher in earlier days and then was reduced by day 28 . So the probiotic inoculation had lasting effects on the development of the community rather than establishing dominance (Baldwin et al., 2018).

\section{LAB as Anti-Campylobacter Probiotics for Poultry}

Applications of some of probiotic strains are also intended to reduce the numbers of pathogenic microorganisms in the gastrointestinal tract of chickens. Because a positive correlation between the number of Campylobacter in the chickens caeca and the number on carcasses was noted (Reich et al., 2008), any decrease of Campylobacter colonization level should lead to reduced contamination of the food chain. So far, many probiotic strains have been described that shown the ability to modulate intestinal microflora and the potential to reduce the number of enteropathogenic bacteria in poultry intestine. Research carried out prior to 2016 in relation to Campylobacter and Salmonella has been reviewed extensively by Saint-Cyr et al. (2016) and Gaggia et al. (2010).

A variety of bacteria (Bacillus, Bifidobacterium, Enterococcus, Lactobacillus, Streptococcus, and Lactococcus spp.) has been tested as probiotics in poultry (Lutful Kabir, 2009), but most of the studies focused on genus Lactobacillus, whose representatives belong to LAB group. Lactobacillus sp. naturally occur on raw food and feed materials, but it also natively resides in the chicken gastrointestinal tract. In chickens, treatment with various members of the Lactobacillus species has been shown to stimulate multiple aspects of the immune response (Lutful Kabir, 2009). Recently, Sefcova et al. conducted studies on the immune mechanisms underlying the intestinal response to Campylobacter infection in the presence of the probiotic L. fermentum CCM7514. The results indicate that the administration of $L$. fermentum to 4 day old chickens exerts a positive effect on the intestinal architecture of birds exposed to pathogens and favorably regulates the expression of pro-inflammatory cytokines, which may lead to a more effective response to Campylobacter invasion. Unfortunately, no studies directly addressed the effect of Lactobacillus on the level of chicken intestine colonization by Campylobacter (Sefcova et al., 2020a,b).

Lactobacillus spp. constitute a diverse group of microorganisms in regard to their physiological attributes and genetic constitution. The strains are characterized not only by a varying ability to survive in the intestinal environment, but also by a type of interaction with epithelial surfaces and immune cells. The differences are noticeable even among strains of the same species; therefore, a careful consideration is needed during the selection of strains for probiotic preparations. It was even shown, albeit admittedly in mice, that different strains of the same species within phylum Lactobacillus may act in the opposite manner: L. reuteri L6798 was associated with weight gain, whereas $L$. reuteri ATCCPTA4659 was associated with weight loss (Fak and Backhed, 2012).

There are numerous reports of the antagonistic activity of Lactobacillus strains against Campylobacter, which is very often associated with the production of organic acids and/or bacteriocins. The ability of Lactobacillus to adhere to the intestinal epithelium is closely related to the concept of competitive exclusion (CE) and is also one of the most important selection criteria for probiotic strains. The adherence allows microorganisms to survive and temporarily colonize the digestive system, which is necessary to induce beneficial effects on the host, and is assessed by in vitro examination of aggregation, hydrophobicity of cell wall, and adhesion to extracellular proteins including intestinal mucus, fibronectin, and basement membrane matrix (Edelman et al., 2002; Gusils et al., 2003; Bouzaine et al., 2005; Rocha et al., 2012). For example, Lactobacillus rhamnosus LGG reduces adhesion efficacy of $C$. jejuni most significantly under co-culture conditions (Sikic Pogacar et al., 2020). Khaled Taha-Abdelaziz et al. have shown that five Lactobacillus spp. (L. salivarius, L. johnsonii, L. reuteri, L. crispatus, and $L$. gasseri) exhibited also an anti-Campylobacter activity in vitro. Organic acids produced by examined Lactobacillus strains lead to the destabilization of the Campylobacter cell wall and are responsible, at least partially, for inhibiting the pathogen growth. It was also found that the tested strains inhibited the production of the quorum sensing autoinducer-2 molecule by $C$. jejuni and decreased the expression of genes related to virulence, including the genes responsible for motility (flaA, flaB, and flhA). Moreover, treatment of chickens macrophages with these lactobacilli enhances their phagocytic activity against $C$. jejuni. These results suggest that the administration of probiotic lactobacilli to chickens may not only reduce $C$. jejuni colonization, but may also impair $C$. jejunis ability to survive and invade intestinal epithelial cells (Taha-Abdelaziz et al., 2019).

There have been many studies showing the possibility of using LAB strains as anti-Campylobacter probiotics. However, much less research confirms the effectiveness of these preparations in vivo. Promising results were obtained by teams of M. Konkel and E. K. Jagusztyn-Krynicka. They observed that the administration of the Lactobacillus genus, i.e., L. crispatus, L. salivarius, L. helveticus, and L. gallinarum, to chickens leads to a reduction of the colonization level of bird cecum by Campylobacter (Neal-McKinney et al., 2012; Kobierecka et al., 2017). Mañes-Lázaro et al. described that Lactobacillus johnsonii FI9785 has the potential to control C. jejuni infection; however, it depends strictly on successful probiotic colonization (ManesLazaro et al., 2017). Nishiyama et al. showed that Lactobacillus gasseri SBT2055 suppressed C. jejuni colonization by c. 250 -fold (Nishiyama et al., 2014) and identified a cell surface-associated aggregation-promoting factor APF1 as being important both for colonization of chickens and for reducing colonization by C. jejuni in vivo (Nishiyama et al., 2015). There is also a lot of research showing that the use of multispecies probiotics has a positive effect. Administration of a mixture of five strains (L. salivarius, L. reuteri, E. faecium, Pediococcus acidilactici, and Bifidobacterium) to chicken was effective in reducing C. jejuni colonization in vivo, giving a mean $6 \log 10$ reduction compared with controls (Ghareeb et al., 2012). Addition of multispecies probiotic (Lavipan, JHJ, Poland) composed of Lactococcus lactis, Carnobacterium divergens, L. casei, $L$. 
plantarum, and Saccharomyces cerevisiae to a feed for broiler chickens was capable to reduce slightly the extent of Campylobacter spp. (Smialek et al., 2018). This is one of the few studies to date, that have evidenced a possible role of probiotics in preventing the shedding of Campylobacter spp. under field conditions, at the level of production (Smialek et al., 2018). Among the birds that received the probiotic, no Campylobacter was found in $25 \%$ of the intestinal samples and $100 \%$ of the pectoral muscles samples, while in the control group, growth of Campylobacter was observed in 100 and 50\%, appropriately. The commonly used research facilities typically do not reflect field conditions, which include numerous on-farm sources of Campylobacter leading to possible recontamination of the flock during the rearing period. Thus the action of probiotic products should be validated through on-farm trials. The evaluation of the effectiveness in reducing Campylobacter of commercial feed additives was carried out by Mortada et al. It turned out that although the in vitro results indicated the effectiveness of the preparations used, in vivo, none of the treatments influenced the Campylobacter load in the cecum at the age of 42 days (Mortada et al., 2020). The presented studies are summarized in Table 2.

Limiting Campylobacter in poultry production remains therefore a continuing challenge. Dissecting complex interactions between Campylobacter and the GIT resident microbial community as well as immune system of the bird appear to be a necessary step facilitating development of an effective probiotic preparation.

Probiotics combined with prebiotics form synbiotics. Prebiotics are a non-viable food component that confer health benefit(s) on the host associated with modulation of the microbiota. In the last decade, the use of synbiotic supplements in poultry flocks has been intensively investigated. The prebiotics applicated most often were galacto-oligosaccharides (GOS), fructooligosaccharides, or xylooligosaccharides (XOS). Baffoni et al. showed that $B$. longum PCB133 associated with XOS is effective in reducing $C$. jejuni colonization. Moreover, it turned out that the administration of this synbiotic at the beginning of animal life when the gut microbiota is still under development and more susceptible to changes is more effective (Baffoni et al., 2017). Last presented study showed that dietary supplementation with the prebiotic GOS affects the number of autochthonous synbiotic species in the intestines, precisely L. johnsonii. This is linked to improved performance and the expression of cytokines and chemokines significant to prime innate intestinal immune systems (Richards et al., 2020).

\section{Lactic Acid Bacteria as Vaccine Vehicle}

Due to its beneficial properties, LAB is common components in commercial probiotics used in poultry agriculture. Recently, an increasing attention has been paid to their new potential biomedical application as a live oral vaccine delivery platform (live vaccine vector). In this respect, the most promising research is carried out on L. lactis and several species of the genus Lactobacillus: L. rhamnosus, L. casei, L. bulgaricus, L. salivarius, L. plantarum, L. acidophilus, L. helveticus, L. gasseri, and Streptococcus gordonii.
In recent years, several studies have explored the use of genetically modified $L$. lactis and some Lactobacillus spp. to express conserved Campylobacter antigens. The use of these species has its justification. L. lactis is able to survive in the digestive tract of humans and animals and to establish a transient colonization of the intestine through adhesion to mucus layer (Wang et al., 2011), while some Lactobacillus strains colonize broiler chicks more persistently and at a higher level (Spivey et al., 2014).

All the strategies proposed so far are based on lactic acid bacteria strains displaying different $C$. jejuni antigens on their surface. Many types of proteins are attached to the cell walls of Gram-positive bacteria. Among them are: (i) proteins specifically recognized by sortase and covalently linked to peptidoglycan through an LPxTG motif; (ii) proteins attached in a non-covalent manner through specific protein domains (LysM or SH3 domains); (iii) membrane anchored (lipoprotein); and (iv) proteins having one or more transmembrane domains. The first two strategies for attaching proteins to peptidoglycan are the most popular in vaccine development (Figure 3).

In Kobierecka et al. (2016a) used L. lactis strain presenting two Campylobacter antigens on the cell surface. Using C-terminus of the L. lactis YndF containing the LPTXG motif, they decorated the cell wall with Campylobacter rCjaAD hybrid protein composed of $\mathrm{CjaA}$ antigen presenting $\mathrm{CjaD}$ peptide epitopes (Kobierecka et al., 2016a). CjaA is a glycosylated, strongly immunogenic lipoprotein anchored in the inner membrane of the Campylobacter cell. It is a component of the $\mathrm{ABC}$ transport system with cysteine as its natural ligand (Muller et al., 2005; Wyszynska et al., 2008). While $\mathrm{CjaD}$ is peptidoglycan-associated protein (Pal), a part of the Tol-Pal system which is important for maintaining outer membrane integrity.

The same group also investigated the effectiveness of non-live carrier of Campylobacter antigens: Lactobacillus salivarius GEM particles (Gram-positive enhancer matrix particles which were obtained by chemical pre-treatment of bacterial cells with trichloroacetic acid). GEM particles presented the same two antigens: $\mathrm{CjaA}$ and $\mathrm{CjaD}$ on their surface but this time, the antigens were fused with the protein anchor (PA) of the L. lactis peptidoglycan hydrolase AcmA, which comprises 3 LysM motifs non-covalently bind to peptidoglycan (Kobierecka et al., 2015).

Two more research groups presented a similar strategy. In 2019, Gorain and colleagues used L. lactis strain as a vector and the C. jejuni adhesin, JlpA as the antigen. JlpA is a lipoprotein that interacts with intestinal heat shock protein (Hsp90 $\alpha$ ) and is involved in triggering a pro-inflammatory response. They linked the JlpA protein to the L. lactis protease USP4 signal peptide at the N-terminus and to the M6 protein cell wall anchor motif (with LPxTG sequence) of Streptococcus pyogenes (CWA_M6) at the C-terminus. The presence of the CWA_M6 motif ensured the localization of the JlpA protein on the surface of the bacterial cells. Additionally, it has been proven that the JlpA protein anchored in the peptidoglycan of $L$. lactis cells retains its biological activity (Gorain et al., 2020).

Wang's group proposed yet another method, in which the C. jejuni CjaA antigen was not anchored to the peptidoglycan, but was secreted from the cell. CjaA was coexpressed with 
TABLE 2 | LAB as anti-Campylobacter probiotics for poultry.

\begin{tabular}{|c|c|c|c|c|}
\hline LAB strain & Dose & Administration & Effect & Reference \\
\hline L. fermentum CCM7514 & $\sim 10^{9} \mathrm{CFU} / 0.2 \mathrm{ml}$ & daily for first 7 days of life & $\begin{array}{l}\text { - slight significant increase in weight } \\
\text { - positive regulation of pro- } \\
\text { inflammatory cytokine expression } \\
\text { (upregulation of some type II } \\
\text { cytokines (IL-4 and IL-13), } \\
\text { downregulation of pro-inflammatory } \\
\text { cytokines IL-15, IL-16, and interferon } \\
\gamma \text { ) }\end{array}$ & Sefcova et al., 2020a,b \\
\hline
\end{tabular}

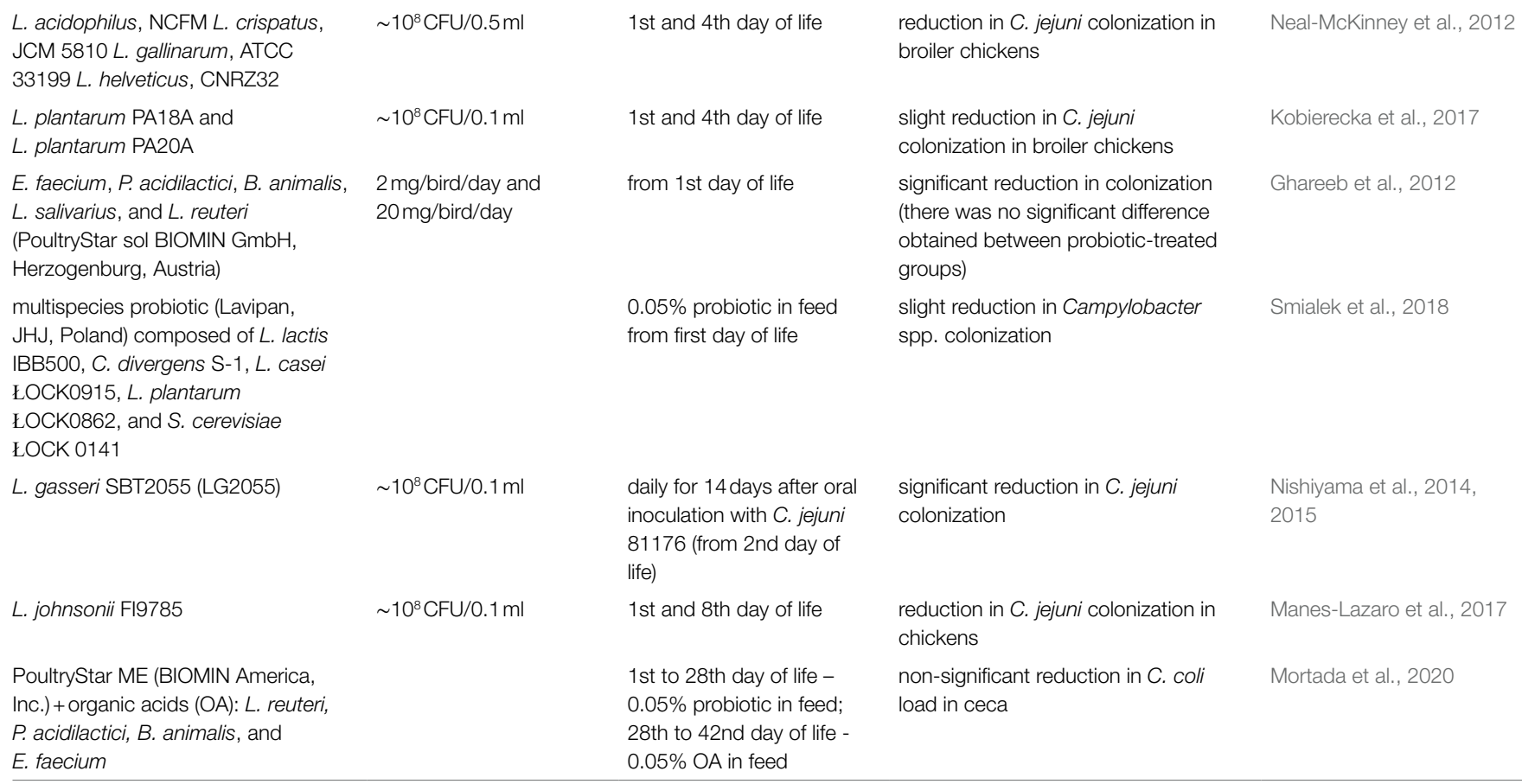

the usp45 signal peptide supporting secretory expression and with the $E$. coli heat labile enterotoxin subunit B, which acted as a mucosal adjuvant (Newsted et al., 2015; Sun et al., 2017; Wang et al., 2020).

All presented strategies were successful and L. lactis cells produced sufficient $C$. jejuni antigens to elicit an immune response in the vaccinated animals. It must be admitted, however, that the protective effect against colonization with Campylobacter was not impressive. Chickens immunized with L. lactis, producing surface exposed hybrid protein $\mathrm{rCjaAD}$, showed moderate $1 \log 10$ reduction of Campylobacter load in the caecum compared to the control group. The vaccine consisting of $L$. salivarius GEM particles presenting on the surface CjaA and CjaD did not produce any protective effect, but GEM L. salivarius particles presenting hybrid $\mathrm{rCjaAD}$ administered in ovo to the chicken embryos slightly lowered the level of intestine colonization by Campylobacter in comparison with the control group (the median reduction of $C$. jejuni cecal contents was $1 \log 10$ for in ovo immunization with GEM particles containing rCjaAD; Kobierecka et al., 2016). A similar effect was obtained when the animals were orally immunized with $L$. lactis expressing the JlpA. Significant reduction in the bacterial load, 7 days post-challenge, was observed in the animals immunized with L. lactis expressing JlpA as well as in the group which was administered subcutaneously with IFA-JlpA antigen (purified JlpA protein emulsified in incomplete Freund's adjuvant) compared to unimmunized birds in the control group. The reduction in C. jejuni colonization demonstrated by Gorain's team was at the same level as the effect described by Kobierecka et al. and amounted $\sim 1 \log 10$ (Kobierecka et al., 2015; Gorain et al., 2020). The immunization of chickens with the L. lactis strain secreting the CjaALtB protein showed no significant protective effect. Initially, 5 days post-challenge, Wang et al. observed a significant reduction of cecal $C$. jejuni (by $2.35 \log 10)$, but 9 days post-challenge, all bird groups were colonized at the same level (Wang et al., 2020). Despite these unsatisfactory results, all research groups showed that the intragastric administration of $L$. lactis cells expressing Campylobacter proteins induced adaptive immune responses in chickens. In the most comprehensive study, Gorain et al. demonstrated significant rise in IgA level in the vaccinated animals compared to the control groups of birds. They also proved that L. lactis expressing JlpA protein activated an innate immune response by triggering TLR-2 intracellular signaling cascade (Gorain et al., 2020).

These results show that $\mathrm{LAB}$, in particular L. lactis, can be an effective platform for the delivery of Campylobacter 


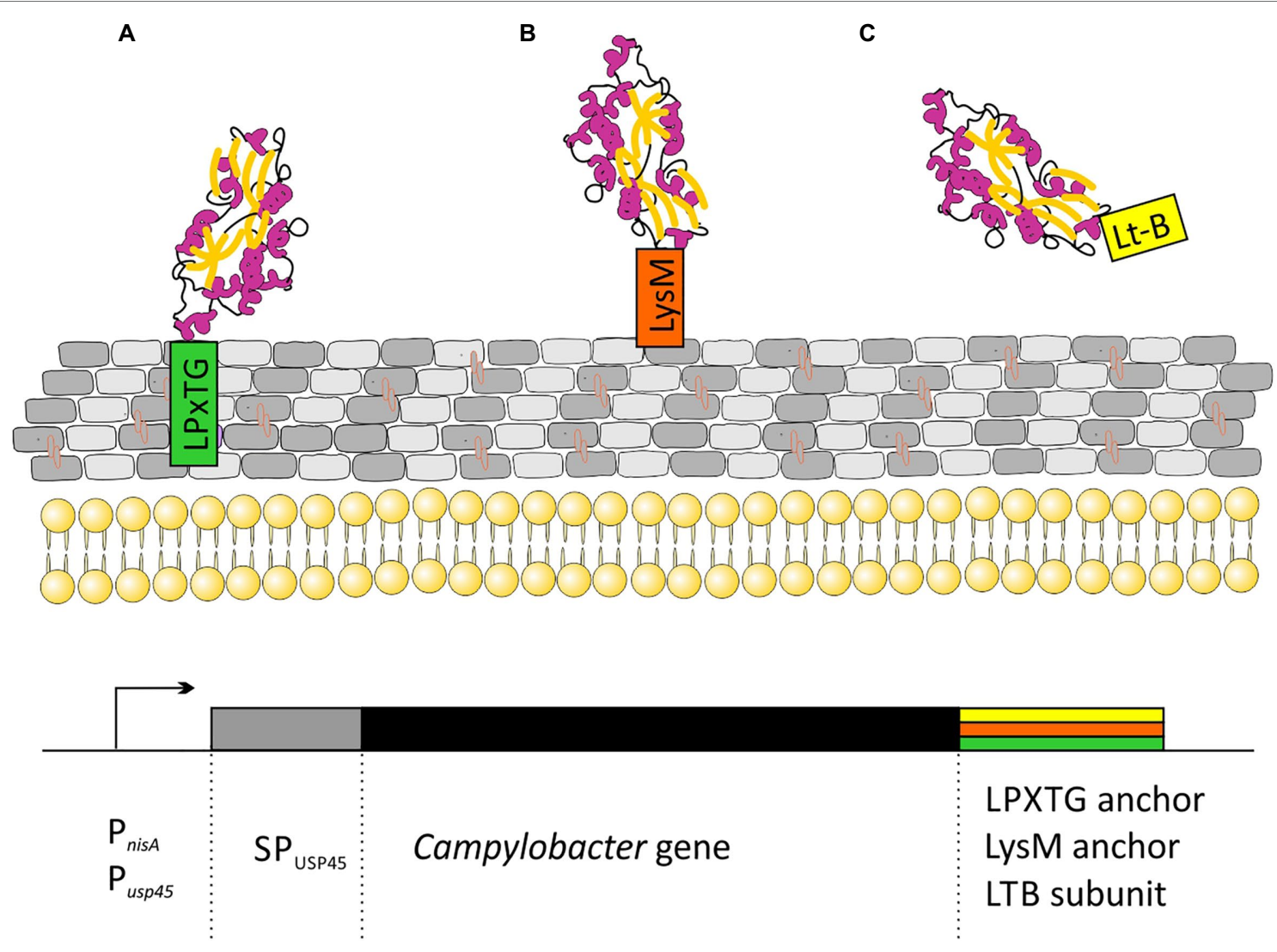

FIGURE 3 | Schematic representation of strategies for the cloning of C. jejuni genes for secretory expression in Lactococcus lactis: (A) Campylobacter protein covalently attached to peptidoglycan via the CWA domain from M6 or YndF proteins; (B) Campylobacter protein non-covalently attached to peptidoglycan via LysM domains from AcmA protein; and (C) secreted Campylobacter protein fused to labile enterotoxin subunit B domain. Transcription of the cloned genes is driven by an nisin-inducible $\mathrm{P}_{\text {nisA }}$ promoter or strong, constitutive $\mathrm{P}_{\text {usp45 }}$ promoter. $\mathrm{SP}_{\text {usp45 }}$ - signal peptide of Usp45, the major Sec-dependent protein secreted by $L$. lactis.

antigens to the immune system of birds, as previously demonstrated with other pathogens, e.g., Avian Influenza Virus Clostridium tetani toxin, Brucella abortus, Rhodococcus equi, and Streptococcus pneumoniae (pneumococcus; Wells et al., 1993; Medina et al., 2010; Cauchard et al., 2011; Saez et al., 2012; Lahiri et al., 2019).

It should be also emphasized that L. lactis-based vaccines are capable of activating both types of the immune response and inducing a specific mucosal response, but the problem of how to enforce the immune response of chickens to get a better protective effect against Campylobacter infection is still awaiting a solution. Therefore, it seems that exploring new Campylobacter antigens and searching for effective adjuvants are still important directions for the further scientific development in this field.

\section{CONCLUSION}

It is estimated that over the next 20 years, chicken production will have to increase 4 -fold to satisfy the growing global demand. Therefore, the sustainable production of safe meat, not only chicken meat, is an international priority. The key question is whether it can be done in a way that does not increase the risk to public health and at the same time protects the health and welfare of animals.

In recent years, there have been more and more reports on taxonomic differences and the development of microbial communities in the gut of farm animals, in particular chickens. The development of affordable next-generation DNA sequencing techniques has made it possible to study the diversity of this important ecosystem in detail and to link changes in microbiota to animal health. Understanding the relationship between microorganisms forming farm animal microbiome might certainly help to develop alternative strategies for replacing antibiotics in modern poultry production and ensuring food safety.

There are high hopes for probiotics at the moment. Subtle manipulations in the composition of the microflora of the gastrointestinal tract, resulting from the use of probiotics, have beneficial effects on maintaining health through diversity, stability of metabolites, and modulation of the immune system. Probiotics modulate the environment of gastrointestinal tract, act synergistically with the immune system host, reduce the risk of digestive tract diseases, and for these reasons they can find applications in animal husbandry. Without a doubt, a thorough understanding of the normal succession in the gut microbiota 
can aid the development and optimization of the probioticbased strategies.

The intention of this paper was to review the current knowledge regarding the ability of probiotic strains to eliminate or reduce the load of dangerous human pathogens in the animal intestinal tract. Excessive growth of pathogenic bacteria in the digestive system is often a result of disordered composition of the intestinal microbiome. The flagship example is an extremely dangerous Clostridium difficile infection in humans subjected to antibiotic therapy. We now know more and more about mutual dependencies between microorganisms. Typical cases include (i) a presence of one microorganism generates a niche for other, pathogenic microorganisms to colonize the host, (ii) one microorganism predisposes the host to be colonized by other microorganisms, and (iii) two or more nonpathogenic microorganisms together cause disease. The gut microbiome is currently considered as a "super organ" involved in a range of disease states. If we learn to heal this super organ, we will get a tool to control some diseases.

Probiotics are one of the possible treatments that demonstrated potential to reduce the intestinal colonization by pathogens. However, their beneficial effect is largely dependent on the type and amount of probiotic bacterial strains used, as well as their dose, method and time of administration. Also, the

\section{REFERENCES}

Abt, M. C., and Artis, D. (2009). The intestinal microbiota in health and disease: the influence of microbial products on immune cell homeostasis. Curr. Opin. Gastroenterol. 25, 496-502. doi: 10.1097/MOG. 0b013e328331b6b4

Andersson, D. I., and Hughes, D. (2014). Microbiological effects of sublethal levels of antibiotics. Nat. Rev. Microbiol. 12, 465-478. doi: 10.1038/nrmicro3270

Apajalahti, J., Kettunen, A., and Graham, H. (2004). Characteristics of the gastrointestinal microbial communities, with special reference to the chicken. World's Poultry Sci. J. 60, 223-232. doi: 10.1079/WPS20040017

Arsi, K., Donoghue, A. M., Woo-Ming, A., Blore, P. J., and Donoghue, D. J. (2015). The efficacy of selected probiotic and prebiotic combinations in reducing campylobacter colonization in broiler chickens. J. Appl. Poult. Res. 24, 327-334. doi: 10.3382/japr/pfv032

Atarashi, K., and Honda, K. (2011). Microbiota in autoimmunity and tolerance. Curr. Opin. Immunol. 23, 761-768. doi: 10.1016/j.coi.2011.11.002

Awad, W. A., Dublecz, F., Hess, C., Dublecz, K., Khayal, B., Aschenbach, J. R., et al. (2016). Campylobacter jejuni colonization promotes the translocation of Escherichia coli to extra-intestinal organs and disturbs the short-chain fatty acids profiles in the chicken gut. Poult. Sci. 95, 2259-2265. doi: 10.3382/ ps/pew151

Awad, W. A., Hess, C., and Hess, M. (2018). Re-thinking the chicken-Campylobacter jejuni interaction: a review. Avian Pathol. 47, 352-363. doi: 10.1080/03079457. 2018.1475724

Awad, W. A., Molnar, A., Aschenbach, J. R., Ghareeb, K., Khayal, B., Hess, C., et al. (2015). Campylobacter infection in chickens modulates the intestinal epithelial barrier function. Innate Immun. 21, 151-160. doi: 10.1177/ 1753425914521648

Baffoni, L., Gaggia, F., Garofolo, G., Di Serafino, G., Buglione, E., Di Giannatale, E., et al. (2017). Evidence of Campylobacter jejuni reduction in broilers with early synbiotic administration. Int. J. Food Microbiol. 251, 41-47. doi: 10.1016/j. ijfoodmicro.2017.04.001

Baldwin, S., Hughes, R. J., Hao Van, T. T., Moore, R. J., and Stanley, D. (2018). At-hatch administration of probiotic to chickens can introduce beneficial changes in gut microbiota. PLoS One 13:e0194825. doi: 10.1371/journal. pone. 0194825 effects on feed intake, microbial fermentation, and intestinal architecture showed a differential pattern between challenged and non-challenged animals. This strongly indicates that there is still a need for further searches for new strains or new combinations of known probiotic strains.

\section{AUTHOR CONTRIBUTIONS}

AW and RG were responsible for the manuscript writing. All authors contributed to the article and approved the submitted version.

\section{FUNDING}

This work was supported by the grants from the National Science Center, Poland (grant no 2016/21/B/NZ6/01141).

\section{ACKNOWLEDGMENTS}

We thank Dr. Lech Trzeciak for the critical reading of the manuscript.

Ballou, A. L., Ali, R. A., Mendoza, M. A., Ellis, J. C., Hassan, H. M., Croom, W. J., et al. (2016). Development of the Chick Microbiome: How Early Exposure Influences Future Microbial Diversity. Front. Vet. Sci. 3:2. doi: 10.3389/ fvets.2016.00002

Baurhoo, B., Ferket, P. R., and Zhao, X. (2009). Effects of diets containing different concentrations of mannanoligosaccharide or antibiotics on growth performance, intestinal development, cecal and litter microbial populations, and carcass parameters of broilers. Poult. Sci. 88, 2262-2272. doi: 10.3382/ ps.2008-00562

Bermudez-Brito, M., Plaza-Diaz, J., Munoz-Quezada, S., Gomez-Llorente, C., and Gil, A. (2012). Probiotic mechanisms of action. Ann. Nutr. Metab. 61, 160-174. doi: 10.1159/000342079

Borda-Molina, D., Seifert, J., and Camarinha, S. A. (2018). Current Perspectives of the Chicken Gastrointestinal Tract and Its Microbiome. Computat. Struct. Biotechnol. J. 16, 131-139. doi: 10.1016/j.csbj.2018.03.002

Borda-Molina, D., Vital, M., Sommerfeld, V., Rodehutscord, M., and Camarinha-Silva, A. (2016). Insights into Broilers' Gut Microbiota Fed with Phosphorus, Calcium, and Phytase Supplemented Diets. Front. Microbiol. 7:2033. doi: 10.3389/fmicb.2016.02033

Bouzaine, T., Dauphin, R. D., Thonart, P., Urdaci, M. C., and Hamdi, M. (2005). Adherence and colonization properties of Lactobacillus rhamnosus TB1, a broiler chicken isolate. Lett. Appl. Microbiol. 40, 391-396. doi: 10.1111/j. 1472-765X.2005.01684.X

Boyd, Y., Herbert, E. G., Marston, K. L., Jones, M. A., and Barrow, P. A. (2005). Host genes affect intestinal colonisation of newly hatched chickens by Campylobacter jejuni. Immunogenetics 57, 248-253. doi: 10.1007/ s00251-005-0790-6

Buckley, A. M., Wang, J., Hudson, D. L., Grant, A. J., Jones, M. A., Maskell, D. J., et al. (2010). Evaluation of live-attenuated Salmonella vaccines expressing Campylobacter antigens for control of C. jejuni in poultry. Vaccine 28, 1094-1105. doi: 10.1016/j.vaccine.2009.10.018

Byrd, J. A., Hargis, B. M., Caldwell, D. J., Bailey, R. H., Herron, K. L., McReynolds, J. L., et al. (2001). Effect of lactic acid administration in the drinking water during preslaughter feed withdrawal on Salmonella and Campylobacter contamination of broilers. Poult. Sci. 80, 278-283. doi: 10.1093/ ps/80.3.278

Cauchard, S., Bermudez-Humaran, L. G., Blugeon, S., Laugier, C., Langella, P., and Cauchard, J. (2011). Mucosal co-immunization of mice with recombinant 
lactococci secreting VapA antigen and leptin elicits a protective immune response against Rhodococcus equi infection. Vaccine 30, 95-102. doi: 10.1016/j. vaccine.2011.10.026

Cawthraw, S. A., and Newell, D. G. (2010). Investigation of the presence and protective effects of maternal antibodies against Campylobacter jejuni in chickens. Avian Dis. 54, 86-93. doi: 10.1637/9004-072709-Reg.1

Chaveerach, P., Keuzenkamp, D. A., Urlings, H. A., Lipman, L. J., and van Knapen, F. (2002). In vitro study on the effect of organic acids on Campylobacter jejuni/coli populations in mixtures of water and feed. Poult. Sci. 81, 621-628. doi: $10.1093 / \mathrm{ps} / 81.5 .621$

Clavijo, V., and Florez, M. J. V. (2018). The gastrointestinal microbiome and its association with the control of pathogens in broiler chicken production: a review. Poult. Sci. 97, 1006-1021. doi: 10.3382/ps/pex359

Conlan, A. J., Coward, C., Grant, A. J., Maskell, D. J., and Gog, J. R. (2007). Campylobacter jejuni colonization and transmission in broiler chickens: a modelling perspective. J. R. Soc. Interface 4, 819-829. doi: 10.1098/rsif.2007. 1015

Conlan, A. J., Line, J. E., Hiett, K., Coward, C., Van Diemen, P. M., Stevens, M. P., et al. (2011). Transmission and dose-response experiments for social animals: a reappraisal of the colonization biology of Campylobacter jejuni in chickens. J. R. Soc. Interface 8, 1720-1735. doi: 10.1098/rsif.2011.0125

Connerton, P. L., Richards, P. J., Lafontaine, G. M., O'Kane, P. M., Ghaffar, N., Cummings, N. J., et al. (2018). The effect of the timing of exposure to Campylobacter jejuni on the gut microbiome and inflammatory responses of broiler chickens. Microbiome 6:88. doi: 10.1186/s40168-018-0477-5

Costa, M. C., Stampfli, H. R., Arroyo, L. G., Allen-Vercoe, E., Gomes, R. G., and Weese, J. S. (2015). Changes in the equine fecal microbiota associated with the use of systemic antimicrobial drugs. BMC Vet. Res. 11:19. doi: 10.1186/s12917-015-0335-7

Cressman, M. D., Yu, Z., Nelson, M. C., Moeller, S. J., Lilburn, M. S., and Zerby, H. N. (2010). Interrelations between the microbiotas in the litter and in the intestines of commercial broiler chickens. Appl. Environ. Microbiol. 76, 6572-6582. doi: 10.1128/AEM.00180-10

Dasti, J. I., Tareen, A. M., Lugert, R., Zautner, A. E., and Gross, U. (2010). Campylobacter jejuni: a brief overview on pathogenicity-associated factors and disease-mediating mechanisms. Int. J. Med. Microbiol. 300, 205-211. doi: 10.1016/j.ijmm.2009.07.002

De Cesare, A., Sirri, F., Manfreda, G., Moniaci, P., Giardini, A., Zampiga, M., et al. (2017). Effect of dietary supplementation with Lactobacillus acidophilus D2/CSL (CECT 4529) on caecum microbioma and productive performance in broiler chickens. PLoS One 12:e0176309. doi: 10.1371/journal.pone.0176309

De Los Santos, F., Donoghue, A. M., Venkitanarayanan, K., Metcalf, J. H., Reyes-Herrera, I., Dirain, M. L., et al. (2009). The natural feed additive caprylic acid decreases Campylobacter jejuni colonization in market-aged broiler chickens. Poult. Sci. 88, 61-64. doi: 10.3382/ps.2008-00228

Dibner, J. J., and Richards, J. D. (2005). Antibiotic growth promoters in agriculture: history and mode of action. Poult. Sci. 84, 634-643. doi: 10.1093/ps/84.4.634

Duncan, S. H., Holtrop, G., Lobley, G. E., Calder, A. G., Stewart, C. S., and Flint, H. J. (2004). Contribution of acetate to butyrate formation by human faecal bacteria. Br. J. Nutr. 91, 915-923. doi: 10.1079/BJN20041150

Duquenoy, A., Ania, M., Boucher, N., Reynier, F., Boucinha, L., Andreoni, C., et al. (2020). Caecal microbiota compositions from 7-day-old chicks reared in high-performance and low-performance industrial farms and systematic culturomics to select strains with anti-Campylobacter activity. PLoS One 15:e0237541. doi: 10.1371/journal.pone.0237541

Edelman, S., Westerlund-Wikstrom, B., Leskela, S., Kettunen, H., Rautonen, N., Apajalahti, J., et al. (2002). In vitro adhesion specificity of indigenous Lactobacilli within the avian intestinal tract. Appl. Environ. Microbiol. 68, 5155-5159. doi: 10.1128/AEM.68.10.5155-5159.2002

EFSA (2016). The European Union summary report on trends and sources of zoonoses, zoonotic agents and food-borne outbreaks in 2015. EFSA J. 14:e04634. doi:10.2903/j.efsa.2016.s0512, PMID: 32313573

EFSA and ECDC (2017). The European Union summary report on trends and sources of zoonoses, zoonotic agents and food-borne outbreaks in 2016. EFSA J. 15:228. doi: 10.2903/j.efsa.2017.5077

EFSA and ECDC (2021). The European Union One Health 2019 Zoonoses Report. EFSA J. 19:286. doi: 10.2903/j.efsa.2021.6406

EFSA Panel on Biological Hazards (BIOHAZ) (2011). Scientific opinion on Campylobacter in broiler meat production: control options and performance objectives and/or targets at different stages of the food chain. EFSA J. 9:2105. doi: $10.2903 /$ j.efsa.2011.2190

EMA (2017). Sales of veterinary antimicrobial agents in 30 European countries in 2015. European Surveillance of Veterinary Antimicrobial Consumption EMA/184855/2017.

EMA (2020). Sales of veterinary antimicrobial agents in 31 European countries in 2018. European Surveillance of Veterinary Antimicrobial Consumption EMA/24309/2020.

Fak, F., and Backhed, F. (2012). Lactobacillus reuteri prevents diet-induced obesity, but not atherosclerosis, in a strain dependent fashion in Apoe-/mice. PLoS One 7:e46837. doi: 10.1371/journal.pone.0046837

FAO-WHO (2006). Probiotics in food. health and nutritional properties and guidelines for evaluation. FAO Food Nutr Pap 85. doi:ISBN: 92-5-105513-0

FDA (2015). Federal Register, Vol. 80, No. 106, June 3, 2015, Docket No. FDA-2010-N-0155, RIN0910-AG95.

FDA (2019). Summary report On antimicrobials sold or distributed for use in food-producing animals. Available at: https://www.fda.gov/animal-veterinary/ cvm-updates/fda-releases-annual-summary-report-antimicrobials-sold-ordistributed-2019-use-food-producing

Gaggia, F., Mattarelli, P., and Biavati, B. (2010). Probiotics and prebiotics in animal feeding for safe food production. Int. J. Food Microbiol. 141(Suppl. 1), S15-S28. doi: 10.1016/j.ijfoodmicro.2010.02.031

Gauffin Cano, P., Santacruz, A., Moya, A., and Sanz, Y. (2012). Bacteroides uniformis CECT 7771 ameliorates metabolic and immunological dysfunction in mice with high-fat-diet induced obesity. PLoS One 7:e41079. doi: 10.1371/ journal.pone.0041079

Ghareeb, K., Awad, W. A., Mohnl, M., Porta, R., Biarnes, M., Bohm, J., et al. (2012). Evaluating the efficacy of an avian-specific probiotic to reduce the colonization of Campylobacter jejuni in broiler chickens. Poult. Sci. 91, 1825-1832. doi: 10.3382/ps.2012-02168

Goodfellow, J. A., and Willison, H. J. (2016). Guillain-Barre syndrome: a century of progress. Nat. Rev. Neurol. 12, 723-731. doi: 10.1038/nrneurol. 2016.172

Gorain, C., Singh, A., Bhattacharyya, S., Kundu, A., Lahiri, A., Gupta, S., et al. (2020). Mucosal delivery of live Lactococcus lactis expressing functionally active JlpA antigen induces potent local immune response and prevent enteric colonization of Campylobacter jejuni in chickens. Vaccine 38, 16301642. doi: 10.1016/j.vaccine.2019.12.064

Grazul, H., Kanda, L. L., and Gondek, D. (2016). Impact of probiotic supplements on microbiome diversity following antibiotic treatment of mice. Gut Microbes 7, 101-114. doi: 10.1080/19490976.2016.1138197

Gusils, C., Oppezzo, O., Pizarro, R., and Gonzalez, S. (2003). Adhesion of probiotic lactobacilli to chick intestinal mucus. Can. J. Microbiol. 49, 472478. doi: 10.1139/w03-055

Guyard-Nicodeme, M., Keita, A., Quesne, S., Amelot, M., Poezevara, T., Le Berre, B., et al. (2016). Efficacy of feed additives against Campylobacter in live broilers during the entire rearing period. Poult. Sci. 95, 298-305. doi: $10.3382 / \mathrm{ps} / \mathrm{pev} 303$

Haghighi, H. R., Abdul-Careem, M. F., Dara, R. A., Chambers, J. R., and Sharif, S. (2008). Cytokine gene expression in chicken cecal tonsils following treatment with probiotics and salmonella infection. Vet. Microbiol. 126, 225-233. doi: 10.1016/j.vetmic.2007.06.026

Hald, B., Sommer, H. M., and Skovgard, H. (2007). Use of fly screens to reduce campylobacter spp. introduction in broiler houses. Emerg. Infect. Dis. 13, 1951-1953. doi: 10.3201/eid1312.070488

Han, Z., Pielsticker, C., Gerzova, L., Rychlik, I., and Rautenschlein, S. (2016). The influence of age on campylobacter jejuni infection in chicken. Dev. Comp. Immunol. 62, 58-71. doi: 10.1016/j.dci.2016.04.020

Havelaar, A. H., Ivarsson, S., Lofdahl, M., and Nauta, M. J. (2013). Estimating the true incidence of campylobacteriosis and salmonellosis in the European Union, 2009. Epidemiol. Infect. 141, 293-302. doi: 10.1017/S0950268812000568

He, T., Long, S., Mahfuz, S., Wu, D., Wang, X., Wei, X., et al. (2019). Effects of Probiotics as Antibiotics Substitutes on Growth Performance, Serum Biochemical Parameters, Intestinal Morphology, and Barrier Function of Broilers. Animals 9:985. doi: 10.3390/ani9110985

Hermans, D., Pasmans, F., Heyndrickx, M., Van Immerseel, F., Martel, A., Van Deun, K., et al. (2012a). A tolerogenic mucosal immune response leads to persistent Campylobacter jejuni colonization in the chicken gut. Crit. Rev. Microbiol. 38, 17-29. doi: 10.3109/1040841X.2011.615298 
Hermans, D., Pasmans, F., Messens, W., Martel, A., Van Immerseel, F., Rasschaert, G., et al. (2012b). Poultry as a host for the zoonotic pathogen Campylobacter jejuni. Vector Borne Zoonotic Dis. 12, 89-98. doi: 10.1089/ vbz.2011.0676

Hermans, D., Van Steendam, K., Verbrugghe, E., Verlinden, M., Martel, A., Seliwiorstow, T., et al. (2014). Passive immunization to reduce Campylobacter jejuni colonization and transmission in broiler chickens. Vet. Res. 45:27. doi: $10.1186 / 1297-9716-45-27$

Hilmarsson, H., Thormar, H., Thrainsson, J. H., Gunnarsson, E., and Dadadottir, S. (2006). Effect of glycerol monocaprate (monocaprin) on broiler chickens: an attempt at reducing intestinal Campylobacter infection. Poult. Sci. 85, 588-592. doi: $10.1093 / \mathrm{ps} / 85.4 .588$

Hughes, L., Hermans, P., and Morgan, K. (2008). Risk factors for the use of prescription antibiotics on UK broiler farms. J. Antimicrob. Chemother. 61, 947-952. doi: 10.1093/jac/dkn017

Humphrey, S., Chaloner, G., Kemmett, K., Davidson, N., Williams, N., Kipar, A., et al. (2014). Campylobacter jejuni is not merely a commensal in commercial broiler chickens and affects bird welfare. mBio 5:e01364-14. doi: 10.1128/ mBio.01364-14

Ijaz, U. Z., Sivaloganathan, L., Mckenna, A., Richmond, A., Kelly, C., Linton, M., et al. (2018). Comprehensive longitudinal microbiome analysis of the chicken cecum reveals a shift from competitive to environmental drivers and a window of opportunity for Campylobacter. Front. Microbiol. 9:2452. doi: 10.3389/fmicb.2018.02452

Johnson, T. J., Youmans, B. P., Noll, S., Cardona, C., Evans, N. P., Karnezos, T. P., et al. (2018). A Consistent and Predictable Commercial Broiler Chicken Bacterial Microbiota in Antibiotic-Free Production Displays Strong Correlations with Performance. Appl. Environ. Microbiol. 84:e00362-18. doi: 10.1128/AEM.00362-18

Kaakoush, N. O., Castano-Rodriguez, N., Mitchell, H. M., and Man, S. M. (2015). Global Epidemiology of Campylobacter Infection. Clin. Microbiol. Rev. 28, 687-720. doi: 10.1128/CMR.00006-15

Kaakoush, N. O., Sodhi, N., Chenu, J. W., Cox, J. M., Riordan, S. M., and Mitchell, H. M. (2014). The interplay between Campylobacter and Helicobacter species and other gastrointestinal microbiota of commercial broiler chickens. Gut Pathog. 6:18. doi: 10.1186/1757-4749-6-18

Kaiser, P., Howell, M. M., Fife, M., Sadeyen, J. R., Salmon, N., Rothwell, L., et al. (2009). Towards the selection of chickens resistant to Salmonella and Campylobacter infections. Bull. Mem. Acad. R. Med. Belg. 164, 17-25.

Kalischuk, L. D., Leggett, F., and Inglis, G. D. (2010). Campylobacter jejuni induces transcytosis of commensal bacteria across the intestinal epithelium through M-like cells. Gut Pathog. 2:14. doi: 10.1186/1757-4749-2-14

Khan, S., Moore, R. J., Stanley, D., and Chousalkar, K. K. (2020). The Gut Microbiota of Laying Hens and Its Manipulation with Prebiotics and Probiotics To Enhance Gut Health and Food Safety. Appl. Environ. Microbiol. 86:e00600-20. doi: 10.1128/AEM.00600-20

Kim, S. A., Jang, M. J., Kim, S. Y., Yang, Y., Pavlidis, H. O., and Ricke, S. C. (2019). Potential for Prebiotics as Feed Additives to Limit Foodborne Campylobacter Establishment in the Poultry Gastrointestinal Tract. Front. Microbiol. 10:91. doi: 10.3389/fmicb.2019.00091

Kittler, S., Fischer, S., Abdulmawjood, A., Glunder, G., and Klein, G. (2013). Effect of bacteriophage application on Campylobacter jejuni loads in commercial broiler flocks. Appl. Environ. Microbiol. 79, 7525-7533. doi: 10.1128/ AEM.02703-13

Kobierecka, P. A., Olech, B., Ksiazek, M., Derlatka, K., Adamska, I., Majewski, P. M., et al. (2016a). Cell Wall Anchoring of the Campylobacter Antigens to Lactococcus lactis. Front. Microbiol. 7:165. doi: 10.3389/fmicb.2016.00165

Kobierecka, P. A., Wyszynska, A. K., Aleksandrzak-Piekarczyk, T., Kuczkowski, M., Tuzimek, A., Piotrowska, W., et al. (2017). In vitro characteristics of Lactobacillus spp. strains isolated from the chicken digestive tract and their role in the inhibition of Campylobacter colonization. MicrobiologyOpen 6:e00512. doi: $10.1002 / \mathrm{mbo} .512$

Kobierecka, P. A., Wyszynska, A. K., Gubernator, J., Kuczkowski, M., Wisniewski, O., Maruszewska, M., et al. (2016b). Chicken Anti-Campylobacter Vaccine Comparison of Various Carriers and Routes of Immunization. Front. Microbiol. 7:740. doi: 10.3389/fmicb.2016.00740

Kobierecka, P., Wyszynska, A., Maruszewska, M., Wojtania, A., Zylinska, J., Bardowski, J., et al. (2015). Lactic acid bacteria as a surface display platform for Campylobacter jejuni antigens. J. Mol. Microbiol. Biotechnol. 25, 1-10. doi: $10.1159 / 000368780$
Kumar, S., Chen, C., Indugu, N., Werlang, G. O., Singh, M., Kim, W. K., et al. (2018). Effect of antibiotic withdrawal in feed on chicken gut microbial dynamics, immunity, growth performance and prevalence of foodborne pathogens. PLoS One 13:e0192450. doi: 10.1371/journal.pone.0192450

Lahiri, A., Sharif, S., and Mallick, A. I. (2019). Intragastric delivery of recombinant Lactococcus lactis displaying ectodomain of influenza matrix protein 2 (M2e) and neuraminidase (NA) induced focused mucosal and systemic immune responses in chickens. Mol. Immunol. 114, 497-512. doi: 10.1016/j. molimm.2019.08.015

Lamb-Rosteski, J. M., Kalischuk, L. D., Inglis, G. D., and Buret, A. G. (2008). Epidermal growth factor inhibits Campylobacter jejuni-induced claudin-4 disruption, loss of epithelial barrier function, and Escherichia coli translocation. Infect. Immun. 76, 3390-3398. doi: 10.1128/IAI.01698-07

Lan, Y., Verstegen, M., Tamminga, S., and Williams, B. (2005). The role of the commensal gut microbial community in broiler chickens. Worlds Poult. Sci. J. 61, 95-104. doi: 10.1079/WPS200445

Layton, S. L., Morgan, M. J., Cole, K., Kwon, Y. M., Donoghue, D. J., Hargis, B. M., et al. (2011). Evaluation of Salmonella-vectored Campylobacter peptide epitopes for reduction of Campylobacter jejuni in broiler chickens. Clin. Vaccine Immunol. 18, 449-454. doi: 10.1128/CVI.00379-10

Lee, M. D., and Newell, D. G. (2006). Campylobacter in poultry: filling an ecological niche. Avian Dis. 50, 1-9. doi: 10.1637/7474-111605R.1

Ley, R. E., Hamady, M., Lozupone, C., Turnbaugh, P. J., Ramey, R. R., Bircher, J. S., et al. (2008). Evolution of mammals and their gut microbes. Science 320, 1647-1651. doi: 10.1126/science. 1155725

Lin, J. (2009). Novel approaches for Campylobacter control in poultry. Foodborne Pathog. Dis. 6, 755-765. doi: 10.1089/fpd.2008.0247

Loc Carrillo, C., Atterbury, R. J., El-Shibiny, A., Connerton, P. L., Dillon, E., Scott, A., et al. (2005). Bacteriophage therapy to reduce Campylobacter jejuni colonization of broiler chickens. Appl. Environ. Microbiol. 71, 6554-6563. doi: 10.1128/AEM.71.11.6554-6563.2005

Looft, T., Johnson, T. A., Allen, H. K., Bayles, D. O., Alt, D. P., Stedtfeld, R. D., et al. (2012). In-feed antibiotic effects on the swine intestinal microbiome. Proc. Natl. Acad. Sci. U. S. A. 109, 1691-1696. doi: 10.1073/pnas.1120238109

Lopetuso, L. R., Scaldaferri, F., Petito, V., and Gasbarrini, A. (2013). Commensal Clostridia: leading players in the maintenance of gut homeostasis. Gut Pathog. 5:23. doi: 10.1186/1757-4749-5-23

Lutful Kabir, S. M. (2009). The role of probiotics in the poultry industry. Int. J. Mol. Sci. 10, 3531-3546. doi: 10.3390/ijms10083531

Ma, L., Xia, Y., Li, B., Yang, Y., Li, L. G., Tiedje, J. M., et al. (2016). Metagenomic Assembly Reveals Hosts of Antibiotic Resistance Genes and the Shared Resistome in Pig, Chicken, and Human Feces. Environ. Sci. Technol. 50, 420-427. doi: 10.1021/acs.est.5b03522

Mandal, R. K., Jiang, T., Wideman, R. F. Jr., Lohrmann, T., and Kwon, Y. M. (2020). Microbiota Analysis of Chickens Raised under Stressed Conditions. Front. Vet. Sci. 7:482637. doi: 10.3389/fvets.2020.482637

Manes-Lazaro, R., Van Diemen, P. M., Pin, C., Mayer, M. J., Stevens, M. P., and Narbad, A. (2017). Administration of Lactobacillus johnsonii FI9785 to chickens affects colonisation by Campylobacter jejuni and the intestinal microbiota. Br. Poult. Sci. 58, 373-381. doi: 10.1080/00071668.2017.1307322

Maougal, R. T., Bargaz, A., Sahel, C., Amenc, L., Djekoun, A., Plassard, C., et al. (2014). Localization of the Bacillus subtilis beta-propeller phytase transcripts in nodulated roots of Phaseolus vulgaris supplied with phytate. Planta 239, 901-908. doi: 10.1007/s00425-013-2023-9

Maron, D. F., Smith, T. J., and Nachman, K. E. (2013). Restrictions on antimicrobial use in food animal production: an international regulatory and economic survey. Glob. Health 9:48. doi: 10.1186/1744-8603-9-48

Martinez, E. A., Babot, J. D., Lorenzo-Pisarello, M. J., Apella, M. C., and Chaia, A. P. (2016). Feed supplementation with avian Propionibacterium acidipropionici contributes to mucosa development in early stages of rearing broiler chickens. Benef Microbes 7, 687-698. doi: 10.3920/BM2016.0077

Medina, M., Vintini, E., Villena, J., Raya, R., and Alvarez, S. (2010). Lactococcus lactis as an adjuvant and delivery vehicle of antigens against pneumococcal respiratory infections. Bioeng. Bugs 1, 313-325. doi: 10.4161/bbug.1.5.12086

Meijerink, N., Kers, J. G., Velkers, F. C., van Haarlem, D. A., Lamot, D. M., de Oliveira, J. E., et al. (2020). Early Life Inoculation With Adult-Derived Microbiota Accelerates Maturation of Intestinal Microbiota and Enhances NK Cell Activation in Broiler Chickens. Front. Vet. Sci. 7:584561. doi: $10.3389 /$ fvets.2020.584561 
Meng, H., Zhang, Y., Zhao, L., Zhao, W., He, C., Honaker, C. F., et al. (2014). Body weight selection affects quantitative genetic correlated responses in gut microbiota. PLoS One 9:e89862. doi: 10.1371/journal.pone.0089862

Mordor and Intelligence (2018). Europe poultry feed market - segmented by animal, ingredients, supplements, and country - growth, trends, and forecast (2018-2023). Available at: https://www.mordorintelligence.com/industry-reports

Morgun, A., Dzutsev, A., Dong, X., Greer, R. L., Sexton, D. J., Ravel, J., et al. (2015). Uncovering effects of antibiotics on the host and microbiota using transkingdom gene networks. Gut 64, 1732-1743. doi: 10.1136/ gutjnl-2014-308820

Morishita, T. Y., Aye, P. P., Harr, B. S., Cobb, C. W., and Clifford, J. R. (1997). Evaluation of an avian-specific probiotic to reduce the colonization and shedding of Campylobacter jejuni in broilers. Avian Dis. 41, 850-855. doi: $10.2307 / 1592338$

Mortada, M., Cosby, D. E., Akerele, G., Ramadan, N., Oxford, J., Shanmugasundaram, R., et al. (2021). Characterizing the immune response of chickens to Campylobacter jejuni (Strain A74C). PLoS One 16:e0247080. doi: 10.1371/journal.pone.0247080

Mortada, M., Cosby, D. E., Shanmugasundaram, R., and Selvaraj, R. K. (2020). In vivo and in vitro assessment of commercial probiotic and organic acid feed additives in broilers challenged with Campylobacter coli. J. Appl. Poult. Res. 29, 435-446. doi: 10.1016/j.japr.2020.02.001

Mueller, S., Saunier, K., Hanisch, C., Norin, E., Alm, L., Midtvedt, T., et al. (2006). Differences in fecal microbiota in different European study populations in relation to age, gender, and country: a cross-sectional study. Appl. Environ. Microbiol. 72, 1027-1033. doi: 10.1128/AEM.72.2.1027-1033.2006

Muller, A., Thomas, G. H., Horler, R., Brannigan, J. A., Blagova, E., Levdikov, V. M., et al. (2005). An ATP-binding cassette-type cysteine transporter in Campylobacter jejuni inferred from the structure of an extracytoplasmic solute receptor protein. Mol. Microbiol. 57, 143-155. doi: 10.1111/j.1365-2958.2005.04691.x

Nakphaichit, M., Thanomwongwattana, S., Phraephaisarn, C., Sakamoto, N., Keawsompong, S., Nakayama, J., et al. (2011). The effect of including Lactobacillus reuteri KUB-AC5 during post-hatch feeding on the growth and ileum microbiota of broiler chickens. Poult. Sci. 90, 2753-2765. doi: 10.3382/ps.2011-01637

Neal-McKinney, J. M., Lu, X., Duong, T., Larson, C. L., Call, D. R., Shah, D. H., et al. (2012). Production of organic acids by probiotic lactobacilli can be used to reduce pathogen load in poultry. PLoS One 7:e43928. doi: 10.1371/journal. pone.0043928

Newell, D. G., Elvers, K. T., Dopfer, D., Hansson, I., Jones, P., James, S., et al. (2011). Biosecurity-based interventions and strategies to reduce Campylobacter spp. on poultry farms. Appl. Environ. Microbiol. 77, 8605-8614. doi: 10.1128/ AEM.01090-10

Newsted, D., Fallahi, F., Golshani, A., and Azizi, A. (2015). Advances and challenges in mucosal adjuvant technology. Vaccine 33, 2399-2405. doi: 10.1016/j.vaccine.2015.03.096

Ng, S. C., Hart, A. L., Kamm, M. A., Stagg, A. J., and Knight, S. C. (2009). Mechanisms of action of probiotics: recent advances. Inflamm. Bowel Dis. 15, 300-310. doi: 10.1002/ibd.20602

Nishiyama, K., Nakazato, A., Ueno, S., Seto, Y., Kakuda, T., Takai, S., et al. (2015). Cell surface-associated aggregation-promoting factor from Lactobacillus gasseri SBT2055 facilitates host colonization and competitive exclusion of Campylobacter jejuni. Mol. Microbiol. 98, 712-726. doi: 10.1111/mmi.13153

Nishiyama, K., Seto, Y., Yoshioka, K., Kakuda, T., Takai, S., Yamamoto, Y., et al. (2014). Lactobacillus gasseri SBT2055 reduces infection by and colonization of Campylobacter jejuni. PLoS One 9:e108827. doi: 10.1371/journal.pone.0108827

Nobel, Y. R., Cox, L. M., Kirigin, F. F., Bokulich, N. A., Yamanishi, S., Teitler, I., et al. (2015). Metabolic and metagenomic outcomes from early-life pulsed antibiotic treatment. Nat. Commun. 6:7486. doi: 10.1038/ncomms8486

Nothaft, H., Davis, B., Lock, Y. Y., Perez-Munoz, M. E., Vinogradov, E., Walter, J., et al. (2016). Engineering the Campylobacter jejuni N-glycan to create an effective chicken vaccine. Sci. Rep. 6:26511. doi: 10.1038/srep26511

Oakley, B. B., Buhr, R. J., Ritz, C. W., Kiepper, B. H., Berrang, M. E., Seal, B. S., et al. (2014a). Successional changes in the chicken cecal microbiome during 42 days of growth are independent of organic acid feed additives. BMC Vet. Res. 10:282. doi: 10.1186/s12917-014-0282-8

Oakley, B. B., Lillehoj, H. S., Kogut, M. H., Kim, W. K., Maurer, J. J., Pedroso, A., et al. (2014b). The chicken gastrointestinal microbiome. FEMS Microbiol. Lett. 360, 100-112. doi: 10.1111/1574-6968.12608
Oh, J. K., Pajarillo, E. A. B., Chae, J. P., Kim, I. H., Yang, D. S., and Kang, D. K. (2017). Effects of Bacillus subtilis CSL2 on the composition and functional diversity of the faecal microbiota of broiler chickens challenged with Salmonella Gallinarum. J. Anim. Sci. Biotechnol. 8:1. doi: 10.1186/s40104-016-0130-8

Pan, D., and Yu, Z. (2014). Intestinal microbiome of poultry and its interaction with host and diet. Gut Microbes 5, 108-119. doi: 10.4161/gmic.26945

Pandit, R. J., Hinsu, A. T., Patel, N. V., Koringa, P. G., Jakhesara, S. J., Thakkar, J. R., et al. (2018). Microbial diversity and community composition of caecal microbiota in commercial and indigenous Indian chickens determined using 16s rDNA amplicon sequencing. Microbiome 6:115. doi: 10.1186/ s40168-018-0501-9

Patuzzi, I., Orsini, M., Cibin, V., Petrin, S., Mastrorilli, E., Tiengo, A., et al. (2021). The Interplay between Campylobacter and the Caecal Microbial Community of Commercial Broiler Chickens over Time. Microorganisms 9:221. doi: 10.3390/microorganisms 9020221

Pedroso, A. A., Menten, J. F. M., and Lambais, M. R. (2005). The structure of bacterial community in the intestines of newly hatched chicks. J. Appl. Poult. Res. 14, 232-237. doi: 10.1093/japr/14.2.232

Peng, Q., Zeng, X. F., Zhu, J. L., Wang, S., Liu, X. T., Hou, C. L., et al. (2016). Effects of dietary Lactobacillus plantarum $\mathrm{B} 1$ on growth performance, intestinal microbiota, and short chain fatty acid profiles in broiler chickens. Poult. Sci. 95, 893-900. doi: 10.3382/ps/pev435

Reich, F., Atanassova, V., Haunhorst, E., and Klein, G. (2008). The effects of Campylobacter numbers in caeca on the contamination of broiler carcasses with Campylobacter. Int. J. Food Microbiol. 127, 116-120. doi: 10.1016/j. ijfoodmicro.2008.06.018

Renouf, M., and Hendrich, S. (2011). Bacteroides uniformis is a putative bacterial species associated with the degradation of the isoflavone genistein in human feces. J. Nutr. 141, 1120-1126. doi: 10.3945/jn.111.140988

Richards, P. J., Flaujac Lafontaine, G. M., Connerton, P. L., Liang, L., Asiani, K., Fish, N. M., et al. (2020). Galacto-Oligosaccharides Modulate the Juvenile Gut Microbiome and Innate Immunity To Improve Broiler Chicken Performance. mSystems 5:e00827-19. doi: 10.1128/mSystems.00827-19

Richards, P., Fothergill, J., Bernardeau, M., and Wigley, P. (2019). Development of the Caecal Microbiota in Three Broiler Breeds. Front. Vet. Sci. 6:201. doi: $10.3389 /$ fvets.2019.00201

Rinttila, T., and Apajalahti, J. (2013). Intestinal microbiota and metabolitesImplications for broiler chicken health and performance. J. Appl. Poult. Res. 22, 647-658. doi: 10.3382/japr.2013-00742

Robyn, J., Rasschaert, G., Pasmans, F., and Heyndrickx, M. (2015). Thermotolerant Campylobacter during Broiler Rearing: Risk Factors and Intervention. Compr. Rev. Food Sci. Food Saf. 14, 81-105. doi: 10.1111/1541-4337.12124

Rocha, T. S., Baptista, A. A., Donato, T. C., Milbradt, E. L., Okamoto, A. S., Rodrigues, J. C., et al. (2012). Evaluation of in vitro and in vivo adhesion and immunomodulatory effect of Lactobacillus species strains isolated from chickens. Poult. Sci. 91, 362-369. doi: 10.3382/ps.2011-01803

Rosenquist, H., Nielsen, N. L., Sommer, H. M., Norrung, B., and Christensen, B. B. (2003). Quantitative risk assessment of human campylobacteriosis associated with thermophilic Campylobacter species in chickens. Int. J. Food Microbiol. 83, 87-103. doi: 10.1016/S0168-1605(02)00317-3

Saez, D., Fernandez, P., Rivera, A., Andrews, E., and Onate, A. (2012). Oral immunization of mice with recombinant Lactococcus lactis expressing $\mathrm{Cu}, \mathrm{Zn}$ superoxide dismutase of Brucella abortus triggers protective immunity. Vaccine 30, 1283-1290. doi: 10.1016/j.vaccine.2011.12.088

Sahin, O., Kassem, I. I., Shen, Z., Lin, J., Rajashekara, G., and Zhang, Q. (2015). Campylobacter in Poultry: Ecology and Potential Interventions. Avian Dis. 59, 185-200. doi: 10.1637/11072-032315-Review

Sahin, O., Luo, N., Huang, S., and Zhang, Q. (2003). Effect of Campylobacterspecific maternal antibodies on Campylobacter jejuni colonization in young chickens. Appl. Environ. Microbiol. 69, 5372-5379. doi: 10.1128/ AEM.69.9.5372-5379.2003

Saint-Cyr, M. J., Guyard-Nicodeme, M., Messaoudi, S., Chemaly, M., Cappelier, J. M., Dousset, X., et al. (2016). Recent Advances in screening of Anti-Campylobacter Activity in Probiotics for Use in Poultry. Front. Microbiol. 7:553. doi: 10.3389/fmicb.2016.00553

Salaheen, S., Kim, S. W., Haley, B. J., Van Kessel, J. A. S., and Biswas, D. (2017). Alternative Growth Promoters Modulate Broiler Gut Microbiome and Enhance Body Weight Gain. Front. Microbiol. 8:2088. doi: 10.3389/ fmicb.2017.02088 
Salim, H. M., Kang, H. K., Akter, N., Kim, D. W., Kim, J. H., Kim, M. J., et al. (2013). Supplementation of direct-fed microbials as an alternative to antibiotic on growth performance, immune response, cecal microbial population, and ileal morphology of broiler chickens. Poult. Sci. 92, 20842090. doi: $10.3382 /$ ps.2012-02947

Salyers, A. A., Gupta, A., and Wang, Y. (2004). Human intestinal bacteria as reservoirs for antibiotic resistance genes. Trends Microbiol. 12, 412-416. doi: 10.1016/j.tim.2004.07.004

Sarao, L. K., and Arora, M. (2017). Probiotics, prebiotics, and microencapsulation: a review. Crit. Rev. Food Sci. Nutr. 57, 344-371. doi: 10.1080/10408398. 2014.887055

Scanes, C. G. (2007). The global importance of poultry. Poult. Sci. 86, 10571058. doi: $10.1093 / \mathrm{ps} / 86.6 .1057$

Sefcova, M., Larrea-Alvarez, M., Larrea-Alvarez, C., Karaffova, V., Revajova, V., Gancarcikova, S., et al. (2020a). Lactobacillus fermentum Administration Modulates Cytokine Expression and Lymphocyte Subpopulation Levels in Broiler Chickens Challenged with Campylobacter coli. Foodborne Pathog. Dis. 17, 485-493. doi: 10.1089/fpd.2019.2739

Sefcova, M., Larrea-Alvarez, M., Larrea-Alvarez, C., Revajova, V., Karaffova, V., Koscova, J., et al. (2020b). Effects of Lactobacillus Fermentum Supplementation on Body Weight and Pro-Inflammatory Cytokine Expression in Campylobacter Jejuni-Challenged Chickens. Vet. Sci. 7:121. doi: 10.3390/vetsci7030121

Sekirov, I., Russell, S. L., Antunes, L. C., and Finlay, B. B. (2010). Gut microbiota in health and disease. Physiol. Rev. 90, 859-904. doi: 10.1152/physrev.00045.2009

Sergeant, M. J., Constantinidou, C., Cogan, T. A., Bedford, M. R., Penn, C. W., and Pallen, M. J. (2014). Extensive microbial and functional diversity within the chicken cecal microbiome. PLoS One 9:e91941. doi: 10.1371/journal. pone. 0091941

Sikic Pogacar, M., Langerholc, T., Micetic-Turk, D., Mozina, S. S., and Klancnik, A. (2020). Effect of Lactobacillus spp. on adhesion, invasion, and translocation of Campylobacter jejuni in chicken and pig small-intestinal epithelial cell lines. BMC Vet. Res. 16:34. doi: 10.1186/s12917-020-2238-5

Silva, J., Leite, D., Fernandes, M., Mena, C., Gibbs, P. A., and Teixeira, P. (2011). Campylobacter spp. as a Foodborne Pathogen: A Review. Front. Microbiol. 2:200. doi: 10.3389/fmicb.2011.00200

Singh, K. M., Shah, T., Deshpande, S., Jakhesara, S. J., Koringa, P. G., Rank, D. N., et al. (2012). High through put $16 \mathrm{~S}$ rRNA gene-based pyrosequencing analysis of the fecal microbiota of high FCR and low FCR broiler growers. Mol. Biol. Rep. 39, 10595-10602. doi: 10.1007/s11033-012-1947-7

Singh, K. M., Shah, T. M., Reddy, B., Deshpande, S., Rank, D. N., and Joshi, C. G. (2014). Taxonomic and gene-centric metagenomics of the fecal microbiome of low and high feed conversion ratio (FCR) broilers. J. Appl. Genet. 55, 145-154. doi: 10.1007/s13353-013-0179-4

Smialek, M., Burchardt, S., and Koncicki, A. (2018). The influence of probiotic supplementation in broiler chickens on population and carcass contamination with Campylobacter spp. - field study. Res. Vet. Sci. 118, 312-316. doi: 10.1016/j.rvsc.2018.03.009

Sommer, F., and Backhed, F. (2013). The gut microbiota--masters of host development and physiology. Nat. Rev. Microbiol. 11, 227-238. doi: 10.1038/ nrmicro2974

Spivey, M. A., Dunn-Horrocks, S. L., and Duong, T. (2014). Epithelial cell adhesion and gastrointestinal colonization of Lactobacillus in poultry. Poult. Sci. 93, 2910-2919. doi: 10.3382/ps.2014-04076

Stanley, D., Geier, M. S., Denman, S. E., Haring, V. R., Crowley, T. M., Hughes, R. J., et al. (2013). Identification of chicken intestinal microbiota correlated with the efficiency of energy extraction from feed. Vet. Microbiol. 164, 85-92. doi: 10.1016/j.vetmic.2013.01.030

Stanley, D., Hughes, R. J., Geier, M. S., and Moore, R. J. (2016). Bacteria within the Gastrointestinal Tract Microbiota Correlated with Improved Growth and Feed Conversion: Challenges Presented for the Identification of Performance Enhancing Probiotic Bacteria. Front. Microbiol. 7:187. doi: 10.3389/ fmicb.2016.00187

Stern, N. J., Svetoch, E. A., Eruslanov, B. V., Kovalev, Y. N., Volodina, L. I., Perelygin, V. V., et al. (2005). Paenibacillus polymyxa purified bacteriocin to control Campylobacter jejuni in chickens. J. Food Prot. 68, 1450-1453. doi: 10.4315/0362-028X-68.7.1450

Stern, N. J., Svetoch, E. A., Eruslanov, B. V., Perelygin, V. V., Mitsevich, E. V., Mitsevich, I. P., et al. (2006). Isolation of a Lactobacillus salivarius strain and purification of its bacteriocin, which is inhibitory to Campylobacter jejuni in the chicken gastrointestinal system. Antimicrob. Agents Chemother. 50, 3111-3116. doi: 10.1128/AAC.00259-06

Sun, N., Zhang, R., Duan, G., Peng, X., Wang, C., Fan, Q., et al. (2017). An engineered food-grade Lactococcus lactis strain for production and delivery of heat-labile enterotoxin B subunit to mucosal sites. BMC Biotechnol. 17:25. doi: 10.1186/s12896-017-0345-6

Sureshkumar, S., Lee, H. C., Jung, S. K., Kim, D., Oh, K. B., Yang, H., et al. (2021). Inclusion of Lactobacillus salivarius strain revealed a positive effect on improving growth performance, fecal microbiota and immunological responses in chicken. Arch. Microbiol. 203, 847-853. doi: 10.1007/ s00203-020-02088-3

Swaggerty, C. L., Pevzner, I. Y., He, H., Genovese, K. J., and Kogut, M. H. (2017). Selection for pro-inflammatory mediators produces chickens more resistant to Campylobacter jejuni. Poult. Sci. 96, 1623-1627. doi: 10.3382/ ps/pew 465

Taha-Abdelaziz, K., Astill, J., Kulkarni, R. R., Read, L. R., Najarian, A., Farber, J. M., et al. (2019). In vitro assessment of immunomodulatory and anti-Campylobacter activities of probiotic lactobacilli. Sci. Rep. 9:17903. doi: 10.1038/s41598-019-54494-3

Tarradas, J., Tous, N., Esteve-Garcia, E., and Brufau, A. J. (2020). The Control of Intestinal Inflammation: A Major Objective in the Research of Probiotic Strains as Alternatives to Antibiotic Growth Promoters in Poultry. Microorganisms 8:148. doi: 10.3390/microorganisms8020148

Thibodeau, A., Fravalo, P., Yergeau, E., Arsenault, J., Lahaye, L., and Letellier, A. (2015). Chicken caecal Microbiome Modifications Induced by Campylobacter jejuni Colonization and by a Non-Antibiotic Feed Additive. PLoS One 10:e0131978. doi: 10.1371/journal.pone.0131978

Timmerman, H. M., Veldman, A., van den Elsen, E., Rombouts, F. M., and Beynen, A. C. (2006). Mortality and growth performance of broilers given drinking water supplemented with chicken-specific probiotics. Poult. Sci. 85, 1383-1388. doi: 10.1093/ps/85.8.1383

Tsubokura, K., Berndtson, E., Bogstedt, A., Kaijser, B., Kim, M., Ozeki, M., et al. (1997). Oral administration of antibodies as prophylaxis and therapy in Campylobacter jejuni-infected chickens. Clin. Exp. Immunol. 108, 451-455. doi: 10.1046/j.1365-2249.1997.3901288.x

Turnbaugh, P. J., Ley, R. E., Mahowald, M. A., Magrini, V., Mardis, E. R., and Gordon, J. I. (2006). An obesity-associated gut microbiome with increased capacity for energy harvest. Nature 444, 1027-1031. doi: 10.1038/nature05414 van der Wielen, P. W., Keuzenkamp, D. A., Lipman, L. J., van Knapen, F., and Biesterveld, S. (2002). Spatial and temporal variation of the intestinal bacterial community in commercially raised broiler chickens during growth Microb. Ecol. 44, 286-293. doi: 10.1007/s00248-002-2015-y

Van Deun, K., Pasmans, F., Van Immerseel, F., Ducatelle, R., and Haesebrouck, F. (2008). Butyrate protects Caco-2 cells from Campylobacter jejuni invasion and translocation. Br. J. Nutr. 100, 480-484. doi: 10.1017/S0007114508921693

Vandeputte, J., Martel, A., Canessa, S., Van Rysselberghe, N., De Zutter, L., Heyndrickx, M., et al. (2019). Reducing Campylobacter jejuni colonization in broiler chickens by in-feed supplementation with hyperimmune egg yolk antibodies. Sci. Rep. 9:8931. doi: 10.1038/s41598-019-45380-z

Wagenaar, J. A., Van Bergen, M. A., Mueller, M. A., Wassenaar, T. M., and Carlton, R. M. (2005). Phage therapy reduces Campylobacter jejuni colonization in broilers. Vet. Microbiol. 109, 275-283. doi: 10.1016/j.vetmic.2005.06.002

Wang, Y., Wang, J., and Dai, W. (2011). Use of GFP to trace the colonization of Lactococcus lactis WH-C1 in the gastrointestinal tract of mice. J. Microbiol. Methods 86, 390-392. doi: 10.1016/j.mimet.2011.06.009

Wang, C., Zhou, H., Guo, F., Yang, B., Su, X., Lin, J., et al. (2020). Oral Immunization of Chickens with Lactococcus lactis Expressing cjaA Temporarily reduces Campylobacter jejuni Colonization. Foodborne Pathog. Dis. 17, 366-372. doi: 10.1089/fpd.2019.2727

Wells, J. M., Wilson, P. W., Norton, P. M., Gasson, M. J., and Le Page, R. W. (1993). Lactococcus lactis: high-level expression of tetanus toxin fragment C and protection against lethal challenge. Mol. Microbiol. 8, 1155-1162. doi: 10.1111/j.1365-2958.1993.tb01660.x

Williams, L. K., Sait, L. C., Trantham, E. K., Cogan, T. A., and Humphrey, T. J. (2013). Campylobacter infection has different outcomes in fast- and slowgrowing broiler chickens. Avian Dis. 57, 238-241. doi: 10.1637/10442-110212Reg.1

Witzig, M., Carminha-Silva, A., Green-Engert, R., Hoelzle, K., Zeller, E., Seifert, J., et al. (2015). Spatial Variation of the Gut Microbiota in Broiler Chickens as 
Affected by Dietary Available Phosphorus and Assessed by T-RFLP Analysis and 454 Pyrosequencing. PLoS One 10:e0143442. doi: 10.1371/journal.pone.0143442

Wrzosek, L., Miquel, S., Noordine, M. L., Bouet, S., Joncquel, C.-C. M., Robert, V., et al. (2013). Bacteroides thetaiotaomicron and Faecalibacterium prausnitzii influence the production of mucus glycans and the development of goblet cells in the colonic epithelium of a gnotobiotic model rodent. BMC Biol. 11:61. doi: 10.1186/1741-7007-11-61

Wyszynska, A., Zycka, J., Godlewska, R., and Jagusztyn-Krynicka, E. K. (2008). The Campylobacter jejuni/coli cjaA (cj0982c) gene encodes an N-glycosylated lipoprotein localized in the inner membrane. Curr. Microbiol. 57, 181-188. doi: 10.1007/s00284-008-9171-3

Yegani, M., and Korver, D. R. (2008). Factors affecting intestinal health in poultry. Poult. Sci. 87, 2052-2063. doi: 10.3382/ps.2008-00091

Zommiti, M., Almohammed, H., and Ferchichi, M. (2016). Purification and Characterization of a Novel Anti-Campylobacter Bacteriocin Produced by Lactobacillus curvatus DN317. Probiotics Antimicrob. Proteins 8, 191-201. doi: $10.1007 / \mathrm{s} 12602-016-9237-7$
Conflict of Interest: The authors declare that the research was conducted in the absence of any commercial or financial relationships that could be construed as a potential conflict of interest.

Publisher's Note: All claims expressed in this article are solely those of the authors and do not necessarily represent those of their affiliated organizations, or those of the publisher, the editors and the reviewers. Any product that may be evaluated in this article, or claim that may be made by its manufacturer, is not guaranteed or endorsed by the publisher.

Copyright (c) 2021 Wyszyńska and Godlewska. This is an open-access article distributed under the terms of the Creative Commons Attribution License (CC BY). The use, distribution or reproduction in other forums is permitted, provided the original author(s) and the copyright owner(s) are credited and that the original publication in this journal is cited, in accordance with accepted academic practice. No use, distribution or reproduction is permitted which does not comply with these terms. 